\title{
La salvación de la carne según Ireneo en ADV. HAER. V, 1-14. Breve presentación de conjunto. «Fructus autem operis spiritus est carnis salus» $(\mathrm{V}, 12,4,77 \mathrm{~s})$
}

\author{
Sergio Zañartu, s.j. \\ FACULTAD DE TEOLOGÍA \\ PONTIFICIA UNIVERSIDAD CATÓLICA DE CHILE
}

\section{INTRODUCCIÓN}

Ireneo en los libros III y IV ha demostrado, contra los herejes, la verdad de lo transmitido por la Iglesia con variedad de pruebas de la Escritura. Esto lo prosigue en el libro $\mathrm{V}$, donde se esforzará en traer pruebas a partir de las restantes enseñanzas del Señor y de las epístolas del Apóstol (Praef, 18s). Adv. Haer. V, 1-14, según A. Rousseau ${ }^{1}$, formaría una unidad temática sobre la salvación de la carne, comenzando por su fundamento en la Encarnación. El tratadito de Ireneo se cierra al terminar el capítulo 14 recomendando que se usen pruebas de las Escrituras, que destruyen con facilidad todas las sentencias inventadas por los herejes, como él mismo lo ha demostrado $(14,4,95-98)^{2}$. No pretendo tanto una pro-

Irénée de Lyon, Contre les hérésies V. Éd. critique par A. Rousseau y otros (SC 152), (Du Cerf, Paris 1969), 167-176.

2 El capítulo 15, aunque va a pasar a otro tema, comenzará con los textos de resurrección de Is 26, 19 y 66, 13s; Ez 37, 1-10. 12-14, que, según Rousseau (ib., 177), están en la nueva perspectiva antidualista de afirmar que el Dios Creador es el mismo que se revela en Cristo. Véase V, 15, 1, 41ss. Los últimos capítulos (31-36), con que concluye, el libro $\mathrm{V}$ y la obra de Ireneo, están referidos a la resurrección de los justos y a su reino terrestre, como sintetiza este autor (ib., 186-188). Contra los gnósticos que rechazan toda salvación de la carne, los justos deben encaminarse hacia la incorruptibilidad. La resurrección los introducirá en un reino que es solo un preludio terrestre de la vida incorruptible, y última etapa preparatoria de esta. El festín será en una tierra renovada para la auténtica descendencia de Abraham, el Israel espiritual, conforme a las profecías y a algunas citas del N. T. La reconstruida y magnífica Jerusalén terrestre es un anuncio y preparación de la Jerusalén celeste 
fundización del tema ${ }^{3}$, cuanto una presentación de él en cierto orden, siguiendo muy de cerca, para no perder su riqueza, las propias expresiones de Ireneo, y terminando con una brevísima conclusión.

Ireneo es un autor de pensamiento muy rico y con el frescor de múltiples referencias al texto de la Escritura. En su polémica contra las afirmaciones de los herejes que remecen el fundamento de nuestra fe, y contra sus argumentos, a veces muy burdos, nuestro autor repite y remacha por todas partes la verdad apostólica, en defensa de la salvación de la carne. Con todo, hay ciertos desplazamientos, aún en las alusiones bíblicas a las que recurre. Por eso el avance en la lectura del texto siempre resulta interesante y complementario de lo anterior. El pensamiento de Ireneo tiende a ser complexivo, unitario. Por ejemplo si está tratando de la creación, fácilmente alude a la encarnación redentora y a su cul-

y eterna. Después viene la resurrección universal, el juicio, el descendimiento de la Jerusalén celeste. Han sido necesarias etapas sucesivas en el camino de los justos hacia la incorruptibilidad; el reino del Hijo prepara el reino del Padre. Hay pleno acuerdo entre las predicciones de los apóstoles, las de Cristo y las de los profetas, lo que prueba que hay un solo Dios, Creador y Padre, y un solo Hijo, y un solo género humano llamado a ser imagen y semejanza de Dios por la acción del Hijo y del Espíritu. Respecto a V, 36, puede verse A. Orbe, Teología de San Ireneo. Comentario al Libro V del 'Adversus Haereses' III (BAC Maior, 33), (Editorial Católica, Madrid 1988), 554s; 603s; 646-651. "Este capítulo de la obra urge la verdad inmediata y obvia -la dimensión terrena y carnal- del hombre llamado a la Salud: en sus dos etapas últimas, la del Milenio (reino del Hijo o de los justos), y la del Reino definitivo del Padre» $(i b, 554)$. E. Osborn se expresa así: «Millenarianism is for many a foreign body in the thought of Irenaeus and only at the end of the fifth book does this teaching emerge; but it is needed to fulfil the hope which springs from the recapitulation of all things» (Irenaeus of Lyons, Cambridge Univ. Press, Cambridge 2001, 99s).

3 Como trabajo más conceptual sobre el tema y que engloba toda la obra de Ireneo de cara a los herejes, puede verse, entre otros, la síntesis que nos ofrece R. Polanco, "Gloria enim Dei vivens homo, vita autem hominis visio Dei. Reflexiones sobre el homo vivens en el pensamiento de San Ireneo», en S. Fernández y otros, Multifariam. Homenaje a los profesores Anneliese Meis, Antonio Bentué y Sergio Silva, Anales de la Facultad de Teología, 1 (Nueva Serie). (Suplementos a Teología y Vida, ed. Pontificia Universidad Católica de Chile, Santiago 2010, 159-191. «La salvación como vivificación de la carne es entonces el tema de fondo de la antropología ireneana y el tema que sustenta la frase que estamos estudiando (gloria Dei vivens homo, vita hominis visio Dei» (ib, 167). La carne tiene vida, se salva, por la visión de Dios (cf. ib., passim). Y añade este autor que la relación Espíritu carne es síntesis de la antropología ireneana (ib., 177). 
minación, y viceversa. Igualmente, algunas citas de la Escritura pueden englobar más referencias que las solicitadas directamente por ese punto de la polémica. De esto resulta una riqueza grande de material y una mayor dificultad para procesarlo conceptualmente ${ }^{4}$. Además que en ese procesamiento se puede perder en buena parte el encanto de este autor. Por eso, en las líneas teológicas que vienen a continuación, me esforzaré, en cuanto parezca conveniente, en no destruir los párrafos del autor, en dejarlo hablar a él, siguiendo el texto muy de cerca, aunque entrevere los pasajes. En este tipo de ensayo que apunta a exponer líneas de su pensamiento, es imposible evitar las repeticiones en un autor controversista tan repetitivo y cuyos temas tienden a implicarse mutuamente. Muchas de las referencias numéricas al texto de Ireneo las puse en notas al pie de página, por ejemplo los sitios exactos de muchas citas en latín, para que ellas no distraigan al lector y este así, por las referencias numéricas que quedan en mi texto, pueda orientarse mejor sobre párrafos más amplios

A este propósito quisiera recoger aquí algunas de las conclusiones de Ph. BACQ en su estudio sobre el libro IV. «Tel est l'art d'Irénée: les différentes étapes de l'argumentation se suivent en se fondant savamment l'une dans l'autre, un peu comme les couleurs d'un prisme se superposent d'abord avant de se détacher dans leur tonalité propre. Irénée semble craindre les divisions trop tranchées, le répartitions trop systématiques: tout, chez lui, est lié en un déroulement continu. Ce raffinement dans l'art d'écrire explique la surprise du lecteur moderne, accoutumé aux divisions claires et distinctes: il risque, s'il n'y prend garde, de considérer Irénée comme un écrivain désordonné. Ce serait méconnaitre l'unité théologique propre du Livre IV de l'Adversus Haereses» (De l'ancienne à la nouvelle Alliance selon S. Irénée. Unité du libre IV de l'Adversus Haereses (Le Sycomore), (Lethielleux-Presses Univ. Namur, Paris-Namur 1978, 292). A continuación añade: «La continuité de la pensée est renforcée encore par un procédé littéraire qui revient souvent dans l'exposé: l'annonce d'argumentations postérieures ou le rappel de développements antérieurs» (ib. 293). «Irénée sait toujours exactement où il en est de sa démonstration et ne perd jamais de vue ce qu'il a déjà démontré. Mais plus caractéristiques encore, du point de vue de l'unité de la pensé, sont les annonces de développements postérieurs» (ib.). «Si l'attention avait été attirée sur ce procédé typiquement irénéen d'annonce et de reprise de thémes: elles unifient l'exposé d'un bout à l'autre de l'Adversus haereses et témoignent de l'étonnante cohésion de l'oeuvre d'Irénée» (ib.). "C'est l'unité de l'Écriture qui fait en somme l'unité de la théologie d'Irénée, tant au niveau littéraire qu'au niveau du contenu de l'oeuvre. Le genie d'Irénée consiste essentiellement en ceci: il fait coïncider, avec une superbe maîtrise, la structure formelle de son oeuvre et le message théologique qu'elle exprime (...) ce qui ressort, après une lecture attentive du Livre IV de l'Adversus Haereses, c'est la merveilleuse unité de l'Écriture qu'elle dévoile et fait découvrir dans la diversité de ses harmoniques» (ib. 294). 
de Ireneo a los que estoy refiriéndome. En esta aproximación al texto, que puede llegar a parecer una simple traducción, normalmente no usaré las clásicas comillas para no atiborrar de ellas el texto de este artículo. Esto me permitirá tomarme a veces alguna libertad. Cuando se trate de un comentario mío o de otros autores, lo haré notar. Siguiendo a Orbe me centraré en la versión latina, aunque haya cotejado el texto con sus fragmentos griegos y tenido en cuenta, siguiendo a los especialistas, los aportes de la versión armenia. Así el latín, que ayuda para confrontar con otras partes de la obra de Ireneo, se utilizará para destacar citas explícitas de Ireneo y para todas las citas bíblicas. Sigo el texto latino presentado por Sources Chrétiennes, salvo expresa advertencia. Se trata, pues, de una modesta contribución introductoria al estudio de Ireneo referente a una parte de su obra, que presenta un tema básico en el pensamiento de nuestro autor.

En el final del Prefacio al libro V terminaba Ireneo con la verdad salvífica de la Encarnación de nuestro firme y verdadero maestro, Verbo de Dios, Jesucristo ${ }^{6}$, "qui propter immensam suam dilectionem factus est quod sumus nos, uti nos perficeret esse quod est ipse» (Praef. 37-39)7. Correspondientemente, en el capítulo $1^{\circ}$ comienza con la Encarnación, que será el fundamento de la salvación de la carne. Al término del primer párrafo referente a ella declara que con ella perecieron todas las doctrinas de los herejes. Después aplica esto más particularmente a diversas herejías, como la de los discípulos de Valentín (docetas), los ebionitas, los marcionitas.

\section{Comentario I., 22.}

6 El único que nos puede contar lo del Padre, como nuestro autor dirá a continuación.

7 Y el libro V $(36,3,68-74)$ concluirá con las siguientes frases: «(...) Sapientiam Dei per quam plasma ejus conformatum et concorporatum Filio perficitur, ut progenies ejus primogenitus Verbum descendat in facturam, hoc est in plasma <quod> capiatur ab eo, et factura iterum capiat Verbum et ascendat ad eum, supergrediens angelos et fiens secundum imaginem et similitudinem Dei». A. Orbe sugiere la adición de <quod> en vez de «, et» (Teología de San Ireneo I. Comentario al Libro V del 'Adversus Haereses [BAC Maior, 25] (Madrid 1985), ad l.c.; desde aquí en adelante citada como Comentario I). Véase III, 10, 2, 44-47; 19, 1, 18-28. Cf. otros textos en Polanco, Gloria, 179. 


\section{Algunas líneas teológicas}

\section{Las MANos del PADre ${ }^{8}$. A IMAgen y SEMEJANZA}

Uno de los pilares de la teología del Adversus Haereses es afirmar, contra los herejes, que Dios, el Dios bueno, el Padre, es el Creador del universo. Y, por tanto, podrá salvar la carne (cuerpo, plasma) ${ }^{9}$. Así lo reafirma en V, 4, 1ss. Porque el poder de la bondad no tiene límite. Pero creó por medio de sus dos manos: el Hijo y el Espíritu ${ }^{10}$. El Hijo,

8 Respecto a esta expresión de las «dos manos de Dios», de raíz bíblica, concluye J. Mambrino: «Mais Irénée par son image de mains de Dieu a rendu comme sensible cette proximité ineffable et terrible, et n'a pas diminué la sainteté de Dieu en la montrant presque comme familier (...) il ne cesse pas de la travailler, de la faire et la refaire, depuis la création initiale jusqu’à la Résurrection des morts (...) il touche, il saisit, il étreint, il façonne, il modèle amoureusement» ("Les deux mains de Dieu” dans l'oeuvre de Saint Irénée», NRT LXXIX (1957), 355-370, 369).

9 «En contraste con la tendencia gnóstica a sacrificarlo todo en aras del hombre espiritual divino, excluyendo el elemento ínfimo del ámbito de la Salud, se levanta la tesis eclesiástica cargando el acento sobre la Salud de la carne y olvidando prácticamente la del alma» (A. ORBE, «La definición del hombre en la teología del s. II», Greg XLVIII (1967) 522-576, p. 575). «La definición clásica del hombre "animal racional mortal, susceptible de intelecto y de ciencia", no vale para los autores cristianos del s. II. Los eclesiásticos gustarían de caracterizarlo como "animal racional carnal, susceptible de la visión de Dios", o también "plasma hecho a imagen y semejanza de Dios" con énfasis sobre su origen ínfimo y su destinación divina» (ib. 576).

10 Puede verse también I, 22, 1, 1 -17; IV, Praef. 4, 62-65; IV, 20, 1, 1-23, y las respectivas notas de A.Orbe en Teología de San Ireneo IV. Traducción y comentario del libro IV del Adversus Haereses (BAC Maior, 53) (Madrid 1996), 273-276; Dem 5, etc. "Ahora bien, ya que el Verbo establece, es decir, crea y otorga la consistencia a cuanto es, allí donde el Espíritu pone en orden y en forma la múltiple variedad de las potencias, justa y convenientemente el Verbo es denominado Hijo y el Espíritu, Sabiduría de Dios» ( traducción de E. Romero Pose: S. Ireneo de Lyon, Demostración de la Predicación Apostólica. Introducción, Traducción y Notas [extractadas de la obra de Antonio Orbe] [Fuentes Patrísticas, 2], Ciudad Nueva, Madrid 1992). «Las tres divinas personas ostentan su eficacia en todas las obras de la creación: el Padre crea la substancia o materia prima; el Verbo le da forma o consistencia, como paradigma de todas las especies (e individuos) creadas; el Espíritu Santo imprime en todas ellas el dinamismo que las consuma y adorna en orden a su ejercicio» (A. Orbe, Antropología de San Ireneo ([BAC], Madrid 1969), 63); cf. Íd., Hacia la primera teología de la procesión del Verbo. Estudios Valentinianos I, 1, [Analecta Gregoriana 99], Univ. Gregor., Roma 1958 136s). Según este mismo autor, «Dios Padre, sin concurso alguno, llama al universo del no ser al ser, por un simple acto 
su ministro ${ }^{11}$, va a ser llamado «fabricator» ${ }^{12}$, y existía antes de toda creación ${ }^{13}$. El Espíritu es el que mantiene cohesionado el universo ${ }^{14}$. Y

de voluntad soberana. A Él le corresponde la creación primera (substantia elementorum), en el Universo. El Verbo, como instrumento del Padre, da consistencia

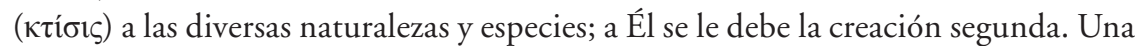
vez subsistentes las esencias, el Espíritu Santo -actuando en servicio inmediato del Verbo- las dota de virtudes y cualidades, consumando en el orden natural la obra de consistencia: y es la $\delta 1 \alpha \kappa o ́ \mu \eta \sigma ı \varsigma ~(=\delta v v \alpha ́ \mu \omega \sigma ı)$ )" (La Unción del Verbo. Estudios Valentinianos III [Analecta Gregoriana, 113], (Univ. Greg., Roma) 1961, 520).

11 «Praedestinati quidem ut essemus qui nondum eramus secundum praescientiam Patris, facti autem (...) in praecognitis temporibus secundum ministrationem Verbi» $(\mathrm{V}, 1,1,15-18)$.

12 «Fabricator enim universorum Dei Verbum, qui et ab initio plasmavit hominem» $(\mathrm{V}, 12,6,121 \mathrm{~s})$.

$13 \mathrm{~V}, 1,1,11$. Orbe traduce así todo el párrafo: «Quienes acabamos de venir al ser medramos por obra del perfecto, anterior a toda creatura, hechos semejantes a él gracias al único óptimo y bueno y con poder para otorgar la incorruptela». Puede verse II, 25, 3, 51-53; 30, 9, 250s; IV, 14, 1, 4-8; 20, 3, 53-56 (El Espíritu junto al Padre antes de toda creación); Dem 10 (véase nota 1 de E. Romero Pose: S. Ireneo de Lyon, Demostración); 30; 52, etc. Respecto a si existía el Verbo antes de ser constituido en orden a la creación, puede verse A. ORBE, p.e. Hacia la primera, 196-198. «Yo me resisto sin embargo a la coexistencia eterna del Hijo y del Espíritu personal, con Dios Padre» (A. ORBE, Estudios sobre la teología cristiana primitiva [Fuentes Patrísticas. Estudios, 1] (Ciudad nueva-Univ. Greg., Madrid-Roma 1994), 7). C. I. GonzÁlez opina lo contrario (“"Creo en un solo Dios, Padre”: la fe de San Ireneo», RevTeolLim XXXIII (99), 73-96, 88ss). Esta opinión contraria es fundamentada por J. Fantino, La théologie d'Irénée. Lectures des Écritures en réponse à l'exégèse gnostique. Une approche trinitaire, Du Cerf, Paris 1994, 338-382. «Finalement, la réalisation du salut exige que le Fils et l'Esprit soient de la même condition et de la même nature que le Père» (ib., 345). Respecto al texto de Dem 43, que tanto ha influido a favor de una posible preexistencia no eterna del Hijo, véase el acucioso artículo de A. Rousseau, quien presupone un original griego diferente y concluye lo contrario («La doctrine de Saint Irénée sur la préexistace du Fils de Dieu dans Dém. 43», Muséon LXXXIX (1971), 5-42).

14 «Per Spiritum Dei qui continet omnia» (V, 2, 3, 53s; cf. Sab 1, 7). «Dans l'oeuvre commune de la création par le Père, le Fils et l'Esprit, Irénée attribue: -au Père: la "volonté", la "décision" ou le "commandement" de créer et le fait de prendre de lui la "substance" des choses créées, -au Fils: l'"execution" ou la "formation", la "forme" et le "modèle" des choses créées, -à l'Esprit: le "parachèvement", la "disposition", l'“ordination" ou l'ornement des choses créées, leur "figure", et également leur "nourriture" et leur "accroissement" (Y. DE ANDIA, HOMO VIVENS. Incorruptibilité et divinisation de l'homme selon IRÉNÉE DE LYON, (Études Augustiniennes, Paris 1986), 67)». «Per hanc igitur ordinationem et hujusmodi convenientiam et tali ductu factus et plasmatus homo secundum imaginem et similitudinem consti- 
Adán, plasmado del limo de la tierra, nunca escapará de estas manos de Dios $^{15}$. Mediante ambas manos, el Padre realiza la Encarnación del Verbo para salvar al hombre que había sucumbido a la muerte. Igualmente, mediante ambas será el paso a la incorrupción ${ }^{16}$, para gloria del Padre ${ }^{17}$. Afirma Ireneo: "Glorificabitur autem Deus in suo plasmate, conforme illud et consequens suo puero adaptans. Per manus enim Patris, hoc est per Filium et Spiritum, fit homo secundum similitudinem Dei, sed non pars hominis» (V, 6, 1, 1-4) ${ }^{18}$. Entretanto Enoch y Elías fueron transferidos (tomados) en sus cuerpos, según los «Presbíteros» al paraíso donde preludian la incorruptibilidad. «Et nihil impedit eos corpus in translationem et assumptionem eorum: per illas enim manus per quas in initio plasmati sunt, per ipsas assumptionem et translationem acceperunt. Assuetae enim erant in Adan manus Dei coaptare et tenere et bajulare suum plasma et ferre et ponere ubi ipsae vellent» (V, 5, 1, 12-18). El tema de las dos manos nos muestra la continuidad y respectiva unidad del plan de Dios hasta la salvación de la carne. «Vani autem omnimodo qui universam dispositionem Dei contemnunt et carnis salutem negant

tuitur infecti Dei, Patre quidem bene sentiente et jubente, Filio vero ministrante et formante, Spiritu vero nutriente et augente, homine vero paulatim proficiente et perveniente ad perfectum, hoc est proximum infecto fieri: perfectus enim est infectus, hic autem est Deus» (IV, 38, 3, 70-78).

15 «Non enim effugit aliquando Adam manus Dei, ad quas Pater loquens dicit: "Faciamus hominem ad imaginem et similitudinem nostram". Et propter hoc in fine "non ex voluntate carnis neque ex voluntate viri" sed ex placito Patris manus ejus vivum perfecerunt hominem, uti fiat Adam secundum imaginem et similitudinem Dei» (V, 1, 3, 83-89). "El plasma humano requiere ser modelado por el Logos (resp. y Sophia), no a causa del limo, más o menos puro, sino a causa del misterio escondido en su formación "a imagen de Dios"» (A. Orbe, "El hombre ideal en la teología de s. Ireneo», Greg XLIII (1962), 449-491, 452).

16 Hablando de la Encarnación, dice Ireneo: «Sic in fine Verbum Patris et Spiritus Dei adunitus antiquae substantiae plasmationis Adae viventem et perfectum effecit hominem, capientem perfectum Patrem»(V, 1, 3, 78-81).

17 "Verbo Dei resurrectionem eis donante “in gloriam Dei Patris” (V, 2, 3, 58s). Cf. $\mathrm{V}, 8,1,17-21$, etc.

18 Orbe traduce así ad 1.c.: «Dios será glorificado en su plasma, adaptándolo en forma y en seguimiento a su Servidor. Mediante las manos del Padre -el Hijo y el Espíritu- hácese en efecto el hombre, no una parte del hombre, a semejanza de Dios». Véase V, 28, 4, 78-80, etc. 
et regenerationem ejus spernunt, dicentes non eam capacem esse incorruptibilitatis» $(\mathrm{V}, 2,2,18-21)^{19}$.

La otra mano, el Espíritu, es eterna, y no como el soplo temporal infundido al hombre para esta vida (cf. V, 12, 2, 30s) ${ }^{20}$. «Aliud enim est afflatus vitae, qui et animalem ${ }^{21}$ efficit hominem, et aliud Spiritus vivificans, qui et spiritalem eum efficit» $(\mathrm{V}, 12,2,14-17)$. El primero se da a todos los habitantes de la tierra, pero el Espíritu solo a los que conculcan las concupiscencias terrenas ${ }^{22}$. "Aliud autem est quod factum est ab eo qui fecit» (V, 12, 2, 29s). Spiritum quidem proprie in Deo deputans (véase Is 57, 16), quem in novissimis temporibus effudit per adoptionem filiorum in genus humanum» $(\mathrm{V}, 12,2,25-27)^{23}$. Respecto a la relación entre la vida temporal y eterna ${ }^{24}$, a propósito del soplo y el Espíritu, es curioso el texto de $\mathrm{V}, 3,3$ donde defendiendo Ireneo el poder de Dios de resucitar a los muertos, de dar la incorrupción a la carne, arguye «ad hominem» contra los contradictores, porque están vivos. Ellos participan, por tanto de la vida y no pueden negarla. Este argumento insinuaría, a mi modo de ver, una cierta continuidad entre la vida temporal y la otra ${ }^{25}$. Y así Ireneo las

19 Si no se salva la carne, tampoco hubo redención ni hay Eucaristía. Según Orbe (Comentario I, 129-132), dado que Ireneo acaba de tratar de los herejes vanos, se referiría aquí a eclesiásticos que negaban la resurrección de los cuerpos.

20 «Et afflatus quidem auctus ad modicum et tempore aliquo manens deinde abit, sine spiramento relinquens illud in quo fuit ante; Spiritus autem circumdans intus et foris hominem, quippe semper perseverans, nunquam relinquet eum» $(\mathrm{V}, 12,2,31-35)$.

21 Hombre psíquico. Destaca J. Fantino el orden de Ireneo como contrario al gnóstico: Il y a d'abord l'homme psychique et ensuite l'homme spirituel. D'abord le premier Adam, ensuite le dernier Adam («Le passage du premier Adam au second Adam comme expression du salut chez Irénée de Lyon», VC LII (1998), 418-429, 420).

22 Véase también V, 18, 2, 29-42.

23 El soplo, corresponde a la condición común, es creado. Lo hecho es otra cosa del que lo hace. Por tanto, el soplo es temporal, mas el Espíritu sempiterno (V, 12, 2, 28-31). "Quemadmodum ab initio plasmationis nostrae in Adam ea quae fuit a Deo aspiratio vitae unita plasmati animavit hominem et animal rationabile ostendit, sic in fine Verbum Patris et Spiritus Dei adunitus antiquae substantiae plasmationis Adae viventem et perfectum effecit hominem, capientem perfectum Patrem, ut, quemadmodum in animali omnes mortui sumus, sic in spiritali omnes vivificemur» $(\mathrm{V}, 1,3,75-83)$.

24 «La vida, junto con ser un atributo de Dios, es también el don de Dios al hombre, y en ese sentido, es la salvación para el ser humano» (Polanco, Gloria, 166).

25 Puede verse Orbe, Comentario I, ad V, 3, 3, 84ss. 
compara distinguiéndolas: «Si autem haec quae est temporalis vita, cum sit multo infirmior quam illa aeterna vita, tamen tantum potens est ut vivificet nostra membra mortalia, cur illa quae est aeterna vita non vivificabit eam carnem quae jam meditata et assueta sit portare vitam?» (V, 3, 3, 78-83).

Como acabamos de ver en V, 1, 3, 83-89, las manos del Padre que habían hecho al hombre a imagen y semejanza de Dios ${ }^{26}$, al final, por el querer del Padre, lo llevaron a cumplimiento (perfecerunt) como hombre viviente a imagen y semejanza. El tema, pues, de la imagen y semejanza recorre también, junto con el del las manos, la teología de Ireneo desde la creación hasta el final ${ }^{27}$. Y según $\mathrm{V}, 6,1,2$ ss, lo que las manos hicieron a semejanza de Dios no es una parte del hombre, como el alma, sino el hombre "perfecto», que es la unión del alma -receptáculo del

26 Puede verse A. Orbe, «Introducción a la teología de los siglos II y III» en Verdad e Imagen 105 (Univ. Gregor.-Sígueme, Roma-Salamanca 1988), cap.13 у 14; B. SESBoüÉ, Tout récapituler dans le Christ. Christologie et sotériologie d'Irénée de Lyon (Jésus et JésusChrist, 80), Declée, Paris 2000) 85-99; J. Fantino, L'homme image de Dieu chez saint Irénée de Lyon (Du Cerf, Paris 1986). "L’image (zǐkóv) exprime la communauté de forme et de substance existant entre tout homme et le Fils incarné (...) Le Fils incarné est l'archétype de l'image. Cependant le Fils, en tant que Fils, n'est pas image du Père; c'est en temps tant? qu'homme que le fils incarné est image de Dieu, manifestant la réalité invisible de Dieu dans sa réalité visible» (Fantino, L'homme image, 178). «Il unifie l'anthropologie (image) et la sotériologie (ressemblance) dans une seule perspective où le Christ se trouve au centre: le Chris est le médiateur de l'image et de la ressemblance, le véritable archétype des deux» (ib., 179). «Parce que dans son humanité il est archétype de l'image, le Fils incarné est principe de la création, parce qu'il communique l'Esprit en tant que Verbe du Père, le Fils incarné est de même principe du salut» (ib., 179). «Pour Irénée, il n'existe pas d'image spirituelle sans substrat matériel. Par conséquent le Fils, en tant que Fils, n'est pas image de Dieu. L'image de Dieu dans l'être humain est le Fils incarné en qui on voit le Père (IV, 6, 6") (Id., Le passage, 424). Para A. Rousseau, imagen y semejanza son correlativos y llegan a ser intercambiables. La imagen plena es el hombre espiritual (Irénée de Lyon, Démonstration de la prédi-



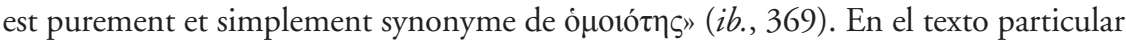
de V, 6, 1 'imagen' se refiere a la semejanza natural, y "semejanza» a la plenitud de perfección que confiere el Espíritu a la imagen (ib., 369-371).

27 Según J. M. Arróniz, «El hombre, por ser libre, es "a semejanza de Dios". Pero con una semejanza radical, históricamente destinada a madurar en el seguimiento al Espíritu, en la unión con el Espíritu» («El hombre "imagen y semejanza de Dios" (Gen. 1, 26) en S. Ireneo", Scriptorium Victoriense XXIII (1976) 275-302, 301). 
Espíritu del Padre y en mezcla con él ${ }^{28}$ - con la carne que es a imagen de Dios. El Espíritu es clave para la similitud, pero la carne (imagen) es necesaria para ser hombre ${ }^{29}$. "Cum autem Spiritus hic commixtus animae unitur plasmati, propter effusionem Spiritus spiritalis et perfectus homo factus est: et hic est qui secundum imaginem et similitudinem factus est Dei. Si autem defuerit animae Spiritus, animalis est vere qui est talis et carnalis derelictus imperfectus erit, imaginem quidem habens in plasmate, similitudinem vero non assumens per Spiritum ${ }^{30}$. Sicut autem hic imperfectus est, sic iterum, si quis tollat imaginem et spernat plasma, jam non hominem intellegere potest» $(\mathrm{V}, 6,1,24-33)$. Por eso, para restaurar al hombre, para que sea a imagen y semejanza, dada la pérdida de esta por el pecado, se necesitaba una nueva infusión del Espíritu. Es necesaria la reintegración y unión de los tres (alma, cuerpo y Espíritu) para la única salvación de ellos ${ }^{31}$. Así el Señor, que verdaderamente se hizo hombre, restauró para su plasma lo hecho en el principio: el hombre había sido hecho según la imagen y semejanza de $\operatorname{Dios}^{32}$. Según Col 3, 10, el hombre nuevo es renovado en el conocimiento, según la imagen del

28 «Perfectus autem homo commixtio et adunitio est animae -assumentis Spiritum Patris et admixtae ei- carni quae est plasmata secundum imaginem Dei» (V, 6, 1, 6-9, según puntuación de Orbe).

29 Orbe se expresa así: «El hombre, substancialmente compuesto de solo dos partes (cuerpo y alma) está a la vez histórica y aun físicamente compuesto de tres: dos substanciales humanas, y una cualitativa (el espíritu divino) procedente de Dios» (Comentario I, 274). «El Espíritu venido de Dios constituye una parte física ('qualitas spiritus') del individuo humano. No por yuxtaposición con el alma, sino por infusión e inhesión en ella» (ib., 278). Solo el justo es hombre perfecto. El tipo ideal del hombre es el Cristo glorioso (ib., 277). Según Andia, «l'image de Dieu est dessinée sur la chair modelée (caro plasmata). Le terme cìí́v ou imago semble toujours garder la note d'extériorité ou de visibilité chez Irénée, à l'inverse de la

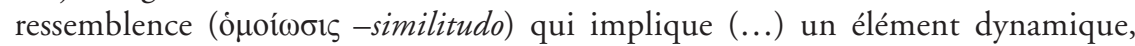
nécessairement requis pour une assimilation spirituelle» (HOMO VIVENS, 68).

30 «La dualidad física (alma y cuerpo) se enriquece notablemente al traducirse (según Gn 1, 26 y 2, 7) en: alma semejante (a Dios por el Espíritu de Él recibido) y cuerpo plásticamente configurado (a imagen del Verbo, Imagen de Dios)» (Orbe, Comentario I, 283). «El alma no es ni la imagen ni la semejanza, pero consigue que la imagen sea imagen efectivamente asemejable al Verbo, perfectible realmente por el Espíritu» (ARrónIz, El hombre «imagen y semejanza», 288).

31 Cf. V, 6, 1, 46-50.

32 Cf. V, 2, 1, 7-10. Los hombres que acogen como injerto la palabra de Dios, vuelven a la naturaleza primitiva, la que fue hecha según la imagen y semejanza de Dios (V, 10, 1, 31-34). Véase V, 16, 2, 29-34, etc. 
que lo creó. Lo de «imagen del Creador», comenta Ireneo, es una recapitulación ${ }^{33}$ del hombre que en un principio fue hecho según la imagen de Dios ${ }^{34}$. Pero ahora solo tenemos las arras del Espíritu. "Quid faciet universa Spiritus gratia quae hominibus dabitur a Deo? Similes nos ei efficiet et perficiet voluntatem Patris: efficiet enim hominem secundum imaginem et similitudinem Dei» $(\mathrm{V}, 8,1,23-26)$.

\section{LA ENCARNACIÓN REDENTORA ${ }^{35}$}

Centrémonos ahora más bien en la Encarnación, que es el fundamento de la vuelta a la imagen y semejanza primitiva, de la salvación de la car-

33 Sobre el uso de recapitulación por Ireneo, puede verse SesBoüÉ, Tout récapituler, cap.6; R. Polanco, "La Encarnación en la teología de San Ireneo de Lyon», en A. Meis y otros, Sapientia Patrum. Homenaje al Profesor Dr. Sergio Zañartu Undurraga, S.J. (Anales de la Facultad de Teología LI, 2 (2000) 43-89, 75-87.

Cf. V, 12, 4, 86-95.

35 C. M. Bondioli afirma: «L'uomo è creato per essere salvato dal Cristo, e non il Cristo viene perché semplicemente c’è l'uomo da salvare» (III, 22, 4) ("Creazione e redenzione in Ireneo de Lione», DivusTh CVII (2004), 11-35, 34). Véase III, 22, 49-55, etc. «L'homme 'rêvé' par Dieu, c'est d'abord l'homme Jésus» (SESBoüÉ, Tout récapituler, 83). Este mismo autor precisa: «Sa pensée tient compte de deux motifs qu'il n'oppose jamais: l'incarnation du Verbe est ordonnée à la divinisation de l'homme et à sa libèration du péché. Parfois, l'auteur associe les deux visées dans le même développement, parfois il met alternativement l'insistance sur l'un ou sur l'autre» (ib., 107). «Entre les deux motifs de l'incarnation du Verbe, il existe sans doute une priorité: Dieu voulait communiquer ses bienfaits à l'homme, avant même l'hypothèse tragique du péché» $(i b ., 111)$. B. MaIlleux, entre una perfección inicial y un progreso hacia ella, estaría por una perfección inicial incoativa («Hérité par l'Esprit: une approche de la théologie du salut chez saint Irénée», Irén LXXV (2002) 147-173. «El primogénito de los muertos fue en definitiva el modelo que Dios tuvo presente al formar al hombre "a su imagen y semejanza"» (A. Orbe, El hombre ideal, 464). «En la economía del no pecado, habría Dios mantenido ciertamente el nacimiento virginal de Jesús y su bautismo en el Espíritu Santo» (ib., 488). Puede verse el sugestivo artículo de R. Polanco, «La carne de Cristo como salus in compendio (AH III, 18, 1) o la gloria de Dios en lo finito. Recepción balthasariana de Ireneo», TeolVid L (2009), 345-373.

J. I. GonzÁlez Faus dedica el cap. 9 a la salvación en la muerte de Cristo en la cruz (Carne de Dios. Significado salvador de la Encarnación en la teología de san Ireneo, Herder, Barcelona 1969). «Una vez aparecido el pecado la cruz pertenece a la encarnación como forma de encarnación en humanidad pecadora (...) La imagen plena del Verbo encarnado no es la del que nació de María, sino la del Cristo glorioso. La resurrección (en cuanto contiene en sí toda la anterior historia de nacimiento y obediencia) es el momento verdadero de la encarnación, en donde se diviniza nuestra naturaleza» (ib., 256s). 
ne. Como vimos al comienzo de este trabajo, el sentido de la Encarnación está dicho al final del prefacio de este libro y sección: «Siguiendo el solo maestro seguro y verdadero, el Verbo de Dios, Jesús Cristo nuestro Señor, quien por su amor sin medida, se hizo lo que nosotros somos

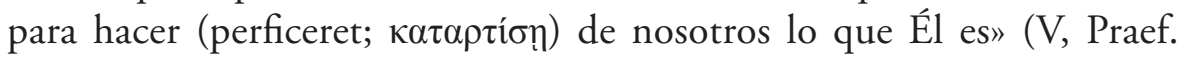
35-39) ${ }^{36}$. Y la Encarnación sigue apareciendo en los párrafos siguientes, por ejemplo, el Verbo «qui est perfectus in omnibus quoniam Verbum potens et homo verus, sanguine suo rationabiliter redimens nos, redemptionem semetipsum dedit pro his qui in captivitatem ducti sunt» $(\mathrm{V}, 1,1,18-22)$. Y justamente el tratadito que estudio va a concluir con otro texto de Encarnación: Carne Domini nostri redemptus es et sanguine ejus redhibitus, «et tenes caput ex quo universum corpus Ecclesiae compaginatum augescit» (Col 2, 19), hoc est carnalem adventum Filii Dei, et Deum confitens ${ }^{37}$ et hominem ejus firmiter excipiens» (V, 14, 4, 91-95). Pero todo el capítulo decimocuarto está dedicado a insistir en la necesidad de la Encarnación verdadera para la salvación de la carne ${ }^{38}$.

36 «Ut fieret filius hominis ad hoc ut et homo fieret filius Dei» (III, 10, 2, 46s). Según V, 36, 2, 37-50, los escalones de la subida son: por el Espíritu al Hijo y por el Hijo al Padre. Véase III, 16, 3, 94-97; 19, 1, 18-28; IV, 20, 5, 111-117, etc.

37 «El Padre, pues, es Señor y el Hijo es Señor; es Dios el Padre y lo es el Hijo, porque el que ha nacido de Dios es Dios. Así según la esencia de su ser y de su poder, hay un solo Dios; pero, al mismo tiempo, en la administración de la economía de nuestra redención, Dios aparece como Padre y como Hijo. Y dado que el Padre del Universo es invisible e inaccesible a los seres creados, es por medio del Hijo como los destinados a acercarse a Dios deben conseguir el acceso al Padre» (Dem, 47, trad. Romero Pose).

38 «Etenim Salvator quidem, quoniam Filius et Verbum Dei; Salutare autem, quoniam Spiritus (...); Salus autem, quoniam caro» (III, 10, 3, 97-100). Según R. Polanco se destacan tres acercamientos a la Encarnación en el Adv Haer: la Encarnación entendida como comunión divinizadora del hombre en Cristo, como visibilización de Dios en Cristo, como recapitulación de todas las cosas en Cristo (La Encarnación en el Adversus Haereses de San Ireneo-Acercamiento a su comprensión, Tesis de licencia en teología dogmática, Facultad de Teología de la Pontificia Universidad Católica, Santiago de Chile 1994); Íd., La Encarnación en la teología de San Ireneo, 43-89. Respecto a lo primero, expresa: "Vemos entonces que Ireneo ha entregado cuatro motivos por los cuales podemos afirmar que la encarnación es salvífica: porque lleva a la carne a la comunión con Dios; porque el Verbo, al asumir lo humano, le da sus cualidades divinas; porque acostumbra paulatinamente al hombre a poseer a Dios; y porque espiritualiza la carne, es decir, la hace capaz de Dios. Todo esto nos hace definir aquí la encarnación como una comunión divinizadora del hombre con Dios» (ib., 62). 
En V, 14, 2, 39-82, afirma Ireneo que el Verbo salvador se hace lo que había sido el hombre, que pereciera, realizando por sí mismo la comu-

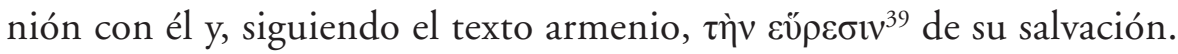
Si el hombre tenía carne y sangre, también el Señor la tuvo, y no una distinta, sino que recapituló en sí la originaria plasmación del Padre en busca de lo que se había perdido. Según Col 1, 22, hemos sido reconciliados en su cuerpo de carne por su muerte. Su carne justa reconcilió la carne prisionera del pecado. Si la carne del Señor fuera de otra substancia no subsistiría la palabra «reconciliación»; tampoco nos redimiría con su sangre ${ }^{40}$. «Et in omni autem epistola manifeste testificatur Apostolus quoniam per carnem Domini nostri et sanguinem ejus nos salvati sumus» (V, 14, 3, 74-77) $)^{41}$. Y concluye nuestro autor que Pablo no dijo, en 1 Co 15, 50, propiamente de la carne y sangre que no puedan heredar el reino de Dios, sino de los actos carnales.

Igualmente afirma Ireneo en este capítulo decimocuarto que el Apóstol no estaba contra la sustancia misma de la carne y la sangre. Usa constantemente carne y sangre respecto a Jesucristo, en parte para establecerlo firmemente como hombre ${ }^{42}$ y en parte para confirmar la salvación de nuestra carne. Porque si la carne no tuviere que ser salvada, tampoco el Verbo de Dios se habría hecho carne, y si no hubiera que reclamar la sangre de los justos, tampoco habría tenido sangre. El Señor, en Mt 23, $35 \mathrm{~s}$, indica la futura recapitulación en sí mismo de la sangre derramada. Luego la sangre debiera ser salvada (V, 14, 1, 1-27). «Nec in semetipsum recapitulatus esset haec Dominus, nisi et ipse caro et sanguis secundum principalem plasmationem factus fuisset, salvans in semetipso in fine illud quod perierat in principio in Adam» (V, 14, 1, 27-31). Por tanto, "Si igitur caro et sanguis sunt quae faciunt nobis vitam, non proprie de carne dictum est et sanguine non posse ea possidere regnum Dei, sed de

39 En vez de 'exquisitionem' (Cf. Rousseau ad l.c.).

40 «Nunc autem per eam quae est ad se communicationem, reconciliavit Dominus hominem Deo Patri, reconcilians nos sibi per corpus carnis suae et sanguine suo redimens nos» (V, 14, 3, 66-69). Ya había dicho Ireneo en V, 2, 1, 6s: «Neque vere redemit nos sanguine suo, si non vere homo factus est».

41 Acaba de citar Ef 1, 7; 2, 13; 2, 14 s.

42 «El filius hominis aplicado al Mesías como "Hombre celeste", según tradición hebrea, adquiere en Ireneo un alcance diametralmente contrario. Dícese "Hijo del hombre", porque nacido de mujer (resp. hombre), hombre de carne y sangre, como los demás» (Orbe, Comentario I, 653). 
praedictis carnalibus actibus qui, ad peccatum transvertentes hominem, privant eum vita» (V, 14, 4, 78-82).

Llama vanos a los valentinianos que dogmatizan diciendo que solo aparentemente era hombre y que nada había recibido de María, para excluir la salvación de la carne ${ }^{43}$ y reprobar la plasmación de Dios. Replica nuestro autor «Neque enim esset vere sanguinem et carnem habens, per quam nos redemit, nisi antiquam plasmationem Adae in semetipsum recapitulasset ${ }^{44}(\mathrm{~V}, 1,2,54-60)^{45}$. Vanos también son los ebionitas, que no admiten la unión de Dios y del hombre ni quieren entender que el Espíritu Santo vino a María y el poder del Altísimo la cubrió con su sombra. Lo que fue generado, pues, es santo e Hijo del Dios altísimo, Padre de todas las cosas, que operó la Encarnación del Hijo e hizo aparecer un nueva generación, para que como habíamos heredado la muerte por la primera generación, así por esta generación heredásemos la vida. No aceptan que Dios se mezcle con ellos (mezcla del vino celeste con el agua terrena). No consideran que como desde el comienzo de nuestra plasmación en Adán el soplo de vida procedente de Dios unido al plasma animó al hombre y lo reveló animal racional, así al final el Verbo del Padre y el Espíritu de Dios unido a la antigua sustancia ${ }^{46}$ de la plasmación de Adán lo hizo hombre viviente y perfecto, que comprende al perfecto Padre, de modo que como en el animal todos morimos, así en el espiritual todos seamos vivificados $(\mathrm{V}, 1,3,61-83)^{47}$. La encarnación

43 El texto pudo decir: excluir la vida de la carne.

$44 \mathrm{~V}, 1,2,56-58$.

45 El párrafo 1, 2 había comenzado: «Vani enim sunt qui putative dicunt eum apparuisse: non enim putative haec, sed in substantia veritatis fiebant» (42-44).

46 «Ireneo no confunde el Verbo del Padre con el Espíritu de Dios. Los supone distintos. Uno es el Verbo personal, mezclado a la humana sustancia en Cristo, desde la Encarnación. Otro es el Espiritu de Dios, derramado sobre la Humanidad de Cristo en el Jordán, y sellado o unido con perfección a ella en su anástasis de entre los muertos» (Orbe, Comentario I, 100).

47 Polanco comenta este trozo en Gloria, 177-180. Dice entre otras cosas: «Se refiere aquí al Hijo y al Espíritu unidos al plasma (= la carne humana plasmada por las manos del Padre en Adán), cada uno a su modo. El Verbo - personalmente- como encarnado, y el Espíritu al colmar la humanidad de Jesús en el Jordán y luego en la resurrección, dejando a la carne de Jesús en plena posesión del Espíritu Santo, como "Hombre espiritual". Se trata de que el plasma de Jesús -su carne- se convierte ahora en "hombre espiritual", viviente y perfecto, para dar ese Espíritu a todos los hombres» (ib., 179). 
también es aludida como abajamiento de lo divino, con intervención del Espíritu, y como subida del hombre a Dios, que termina con la donación de la incorruptibilidad. El texto completo, de rico contenido, es el siguiente: "Suo igitur sanguine redimente nos Domino, et dante animam suam ${ }^{48}$ pro nostra anima et carnem suam pro nostris carnibus, et effundente Spiritum Patris in adunitionem et communionem Dei et hominum, ad homines quidem deponente Deum per Spiritum ${ }^{49}$, ad Deum autem rursus imponente hominem per suam incarnationem, et firme et vere in adventu suo donante nobis incorruptelam per communionem quae est ad eum, perierunt omnes haereticorum doctrinae» $(\mathrm{V}$, $1,1,33-41)$.

La Encarnación salvadora se prolonga en la Eucaristía. Contra los que niegan la salvación de la carne, su capacidad de incorruptibilidad, arguye Ireneo: «Si autem non salvetur haec, videlicet nec Dominus sanguine suo redemit nos, neque calix Eucharistiae communicatio sanguinis ejus est, neque panis quem frangimus communicatio corporis ejus est. Sanguis enim non est nisi a venis et carnibus et a reliqua quae est secundum hominem substantia, quae vere factum Verbum Dei sanguine suo redemit nos» $(\mathrm{V}, 2,2,18-28)$. Por su sangre tenemos la redención, la remisión de los pecados (Col 1, 14). Somos miembros de él, nosotros que somos nutridos por la creación, que él nos otorga ${ }^{50}$. Al cáliz, que viene de la creación, lo declaró sangre suya, por la que se acrecienta nuestra sangre, y al pan, que viene de la creación, lo ratificó cuerpo suyo, por el que medran nuestros cuerpos. "Quando ergo et mixtus calix et factus panis percipit verbum Dei et fit Eucharistia sanguinis et corporis Christi, ex quibus augetur et consistit carnis nostrae substantia, quomodo carnem negant capacem esse donationis Dei quae est vita aeterna, quae sanguine et corpore Christi nutritur et membrum ejus <est $>$ ? ${ }^{51}$. Según

48 Comenta Orbe ad l.c.: «Es esta una de las poquísimas veces que menciona Ireneo el alma de Cristo. Más que ella, le importa el hombre. Menciona psique para urgir la integridad de la redención (del hombre en cuerpo y alma) por Cristo; y, quizás también, para definir de modo implícito su muerte, por separación libre de alma y cuerpo".

49 En V, I, 2, 45s afirma que es Spiritus Dei (el genitivo es explicativo, cf. Rousseau ad 1.c.). En Dem 71 se opone a hombre pasible. Véase nota de Romero Pose a Ireneo de Lión. Demostración, ad l.c.

50 Hace salir el sol y llover.

51 V, 2, 3, 37-42. Véase IV, 18, 5. 
Ef 5, 30 somos miembros de su cuerpo, de su carne y de sus huesos, y no de un hombre espiritual e invisible, sino de la disposición del verdadero hombre, que consta de carnes, nervios y huesos, que se nutre del cáliz, que es su sangre y medra con el pan que es su cuerpo. Y como la planta de la vid fructifica a su tiempo y el grano de trigo disuelto en tierra surge múltiple por el Espíritu de Dios que todo mantiene, y pasan después al uso del hombre, y recibiendo la palabra de Dios se hacen Eucaristía, cuerpo y sangre de Cristo, así también nuestros cuerpos nutridos por ella, enterrados y disueltos en tierra, resurgirán a su tiempo, otorgándoles el Verbo de Dios la resurrección "para gloria de Dios Padre». El Padre reviste con inmortalidad a esto mortal y gratuitamente da la incorruptibilidad a lo corruptible, pues el poder de Dios se consuma en lo débil $(\mathrm{V}, 2,2,28-3,62)^{52}$.

\section{EL ESPÍRITU Y LA DEBILIDAD DE LA CARNE}

A propósito de las manos de Dios y de la imagen y semejanza, habíamos visto que todo el hombre es hecho según la imagen y semejanza de Dios. A la totalidad del hombre dedica Ireneo V, 6, 1. El alma y el Espíritu es solo una parte, pero de ninguna manera el hombre ${ }^{53}$. «Perfectus autem homo commixtio et adunitio est animae assumentis Spiritum Patris et admixtae ei carni quae est plasmata secundum imaginem Dei ${ }^{54}$. Remite a 1 Co 2, 6. El Apóstol llama espirituales a los que participan del Espíri$\mathrm{tu}^{55}$, pero no porque se les haya sustraído la carne. Porque si se sustrae la substancia de la carne y se considera solo el Espíritu, no será un hombre sino Espíritu de hombre o Espíritu de Dios ${ }^{56}$. «Cum autem Spiritus hic

521 Co 15,$53 ; 2$ Co 12, 9.

53 «Este, en su integridad, comporta espíritu y alma; pero, sobre todo, cuerpo (carne). Lo modelado por Dios, mediante el Hijo y el Espíritu, es "per se" el cuerpo; y al cuerpo han de afectar "per se" la imagen y semejanza del Creador» (Orbe, Comentario I, 264).

54 Lín. 6-9.

55 Perfectos, según el apóstol, son los que recibieron el Espíritu de Dios y hablan todas las lenguas mediante él. Oímos que muchos hermanos en la Iglesia tienen los carismas proféticos, hablan todas las lenguas gracias al Espíritu, manifiestan los secretos de los hombres y exponen los misterios de Dios.

56 Comenta Orbe: «Hay en el creyente o justo un spiritus divino ('spiritus Dei'), porque infundido por Dios; y humano ("spiritus hominis"), porque recibido en el hombre y asimilado por él en orden a los actos salvíficos. Un único y mismo 
commixtus animae unitur plasmati, propter effusionem Spiritus spiritalis et perfectus homo factus est: et hic est qui secundum imaginem et similitudinem factus est Dei» ${ }^{57}$. Pero si al alma le falta el Espíritu, es en verdad animal (psíquico), abandonado a la carne, imperfecto, porque posee la imagen en el plasma, pero no la similitud, al no recibir el Espíritu. Pero solos, ni el plasma, ni el alma ni el Espíritu son el hombre, sino partes de él. Es la unión de los tres la que hace al hombre perfecto ${ }^{58}$. Pablo, en relación al hombre perfecto y espiritual, exhorta a conservar íntegros, sin reproche, el Espíritu, alma y cuerpo para la venida del Señor (1 Ts 5, 23 $)^{59}$. Pensaba en la reintegración y unión de los tres y en una única y misma salvación para los tres.

En V, 9, 1 ataca nuestro autor la utilización que hacen los herejes de la frase de Pablo: "Quoniam caro et sanguis regnum Dei hereditare non possunt» (1 Co 15, 50) ${ }^{60}$. Ellos tratan de probar, con esa cita de Pablo, que no hay salvación para la plasmación de Dios. Entonces Ireneo vuelve a que el hombre perfecto consta de carne, alma y Espíritu. El Espíritu es el que salva y configura ${ }^{61}$, y la carne es lo que es salvado («unido»

"spiritus", qualitas spiritus» (Comentario I, 293). «Un mismo Espíritu, que en Dios es substancial, en virtud de su infusión en el alma humana pasa a ser cualidad dinámica (divina) operante en el hombre» (ib. 296). "No hay vestigio en Ireneo -a pesar de II, 33, 4- de un pneuma natural, componente de la estricta physis humana, en oposición al Espíritu de Dios. Un mismo espíritu de Dios, imparticipado en Él (resp. en las tres personas) es indivisamente participado y comunicado al hombre, como "qualitas spiritus" para hacerle "perfecto". (...) Allá donde falte el espíritu, deja el hombre de ser perfecto. Y de divinamente perfecto por participación en el espíritu, pasa a ser hombre animal, o también carnal» (ib., 407s).

$57 \mathrm{~V}, 6,1,24-27$.

58 «Sic iterum, si quis tollat imaginem et spernat plasma, jam non hominem intelligere potest» (V, 6, 1, 31-33).

59 «Perfecti igitur qui et Spiritum semper perseverantem habent Dei et animas et corpora sine querela servaverint» $(\mathrm{V}, 6,1,52-54)$.

60 La frase paulina «quoniam caro et sanguis regnum Dei hereditare (possidere) non possunt» aparece referida unas 11 veces en los capítulos IX al XIV, y nunca en los anteriores.

61 «El Espíritu Santo, al servicio del Padre, para complemento de la demiurgía del Verbo, es la Figuratio Patris. Su misión no reside en revelar o dar a conocer a Dios -como el Verbo, Agnitio Patris-, sino en configurar la carne o deificarla, haciéndola de mortal inmortal, y de corruptible incorruptible, y conformándola según el Cuerpo glorioso del Hijo» (Orbe, Comentario I, 409). J. E. Morales, concluyendo sobre la presencia interior vivificante y permanente del Espíritu en el hombre, 
según texto de Orbe) y formado. Entremedio está el alma, que a veces siguiendo al Espíritu es elevada por este, otras veces, consintiendo con la carne cae en las concupiscencias terrenas. Los que no tienen en sí el Espíritu que salva y forma y da unidad (texto de Orbe) son llamados "carne y sangre», están muertos porque no tienen el Espíritu que vivifica al hombre. Estos se contraponen a los que temen a Dios, creen en la venida del Hijo de Dios y por la fe establecen en su corazón al Espíritu de Dios. Estos son llamados puros, espirituales, vivientes para Dios, porque tienen el Espíritu del Padre que purifica al hombre y lo eleva a la vida de Dios (V, 9, 1, 1-2, 24).

Si la carne es débil, el Espíritu está pronto (Mt 26, 41) y tiene poder para cumplir todo lo que desea (in promptu habet). Si alguien mezcla, como aguijón, la prontitud del Espíritu con la debilidad de la carne, lo poderoso superará a lo débil, la debilidad de la carne será absorbida por la fortaleza del Espíritu y un tal hombre ya no será carnal sino espiritual, por la comunión del Espíritu. Los mártires menospreciaron la muerte, no según la debilidad de la carne sino según la prontitud del Espíritu. La debilidad de la carne, cuando absorbida, manifiesta el poderío del Espíritu, y el Espíritu, que la absorbe, tiene en sí la posesión (hereditate) de la carne. «De ambos ha sido hecho el hombre viviente: viviente por la participación del Espíritu, pero hombre por la sustancia de la carne ${ }^{62}(\mathrm{~V}, 9$, 2, 25-40) ${ }^{63}$. Según V, 9, 3, sin el Espíritu de Dios la carne está muerta, no puede heredar (possidere) el reino de Dios. Es el hombre terrestre (1 Co 15, 48). Pero donde está el Espíritu del Padre, ahí está el hombre viviente: la carne poseída en herencia por el Espíritu, olvidada de sí misma y recibiendo la cualidad del Espíritu, ha sido hecha conforme al

expresa: «la operación propia del Espíritu Santo es el progreso del hombre entendido como el paso de la imagen a la semejanza; la unión de la totalidad natural del hombre con su perfección; la unión de la libertad humana con la acogida del don como capacidad; en síntesis, la comunión del hombre con Dios» (Proficiemus (Adv. Haer. IV, 9, 2). El progreso como obra del Espiritu Santo en el hombre. Una aproximación dogmática al Adversus Haereses de San Ireneo [Tesis de Licencia, Fac. Teol.], Santiago de Chile, 2009, 146).

62 «Et ex utrisque factus est vivens homo, vivens quidem propter participationem Spiritus, homo autem propter substantiam carnis» (V, 9, 2, 38-40).

63 Comenta Polanco (Gloria, 181): «El hombre pasa a ser así testimonio viviente del poder de Dios que transforma (=salva) sin destruir, al contrario de los gnósticos en que Dios para salvar debe destruir la carne». 
Verbo de Dios. Después de citar 1 Cor 15, 49 $9^{64}$, dice nuestro autor que lo terreno es el plasma y lo celeste el Espíritu. Como un tiempo vivimos sin el Espíritu celeste en la vetustez de la carne, así ahora andemos en novedad de la vida, obedeciendo a Dios. Sin el Espíritu de Dios no podemos ser salvados. Por tanto, conservemos el Espíritu de Dios para que no perdamos el reino de los cielos por no participar del Espíritu Santo: la carne y la sangre solas no pueden heredar el reino de Dios.

Según V, 9, 4, a decir verdad, la carne no hereda sino que es poseída en herencia (véase Mt 5,5 ). La tierra, de donde procede la substancia de nuestra carne, es poseída como heredad en el reino. El Señor quiere que el templo esté limpio para que el Espíritu de Dios se deleite en él, como el esposo con la esposa. Como la esposa no puede desposarse con el esposo sino ser desposada por el esposo, así la carne por sí misma (sola) no puede heredar el reino de Dios, sino ser poseída en herencia en el reino por el Espíritu. El que vive es el que hereda lo del muerto ${ }^{65}$. El que vive es el Espíritu de Dios, y lo heredado son los miembros del hombre que se corrompen en la tierra y que transferidos al reino de los cielos son poseídos en herencia por el Espíritu. Cristo murió para liberar a los esclavos y constituirlos después herederos de sus bienes, el Espíritu poseyendo la herencia. El Espíritu (que vive) es el que hereda; la carne es adquirida en herencia. El apóstol dice que la carne y la sangre no pueden heredar el reino de Dios, exhortándonos a la comunión con el Espíritu, para que no perdamos la vida, perdiendo el Espíritu que nos posee en herencia. Como si nos dijera: si el Verbo de Dios no inhabitare y el Espíritu del Padre no estuviere en vosotros, y viviereis vanamente como si solo fuereis carne y sangre, no podréis heredar el reino de Dios.

\section{INJERTO E INHABITACIÓN}

Para explicar que el Espíritu está unido a la carne vivificándola, Ireneo usará la imagen del injerto en V, 10. Pablo teme que complaciendo a la carne, desechemos el injerto del Espíritu (cf. Rm 11, 17.24). Si el olivo permanece silvestre, es tirado al fuego; pero si retiene el injerto y se

64 «Sicult portavimus imaginem ejus qui de terra est, portemus et imaginem ejus qui de caelo est».

65 «Ille (el que posee en herencia) enim dominatur et praeest et disponit, ea quae hereditate possidet quemadmodum ipse velit, illa vero subjecta sunt et obaudiunt et dominantur ab eo et sub dominio sunt ejus qui possidet» (V, 9, 4, 75-78). 
transforma en buen olivo, pasa a ser fructífero. Así los hombres, si progresan hacia lo mejor y reciben el Espíritu de Dios y producen los frutos de este, serán espirituales, como plantados en el jardín de Dios. Pero si desechan al Espíritu y permanecen siendo lo que eran antes, queriendo ser más carne ${ }^{66}$ que Espíritu, entonces muy justamente se dice que la carne y la sangre no heredan el reino de Dios ${ }^{67}$. Los hombres pues, infructuosos respecto a la justicia ${ }^{68}$, pero que reciben, como injerto, la palabra de Dios, vuelven a su naturaleza primitiva, la que fue hecha según la imagen y semejanza de Dios $(\mathrm{V}, 10,1)$. En V, 10, 2 prosigue nuestro autor comparando con el olivo salvaje, y su mudanza por el injerto. Así también el hombre que es injertado por la fe y recibe el Espíritu de Dios, no pierde la sustancia de la carne, pero cambia la cualidad de su fruto: ya no se llama carne y sangre sino hombre espiritual ${ }^{69}$. Pero si no recibe el injerto del Espíritu por la fe, permanece siendo carne y sangre, y no puede tener como herencia el reino de $\operatorname{Dios}^{70}(\mathrm{~V}, 10,2,35-53)$.

Pablo no rechaza la sustancia de la carne sino que atrae la infusión del Espíritu. «Oportet mortale istud induere immortalitatem, et corruptibile hoc induere incorruptelam» (1 Co 15, 53). «Vos autem non estis in carne, sed in Spiritu, siquidem Spiritus Dei habitat in vobis» (Rm 8, 9) ${ }^{71}$. Más claramente en Rm, 8, 10s: «Corpus quidem mortuum propter peccatum, Spiritus autem vita propter justitiam. Si autem Spiritus ejus qui suscitavit Jesum a mortuis habitat in vobis, qui suscitavit Christum a mortuis vivificabit et mortalia corpora vestra propter inhabitantem Spiritum ejus in vobis» ${ }^{72}$. En Rm 8, 13 dice que «Si enim secundum car-

\footnotetext{
66 Texto latino de Orbe.

67 «Mirabiliter igitur Apostolus naturam ostendit nostram et universam dispositionem Dei in eo sermone qui est de carne et sanguine et oleastro» (V, 10, 1, 17-19).

68 «Et homines in neglegentia constituti et concupiscentias carnis tamquam silvestria fructificantes secundum suam causam infructuosi justitia constituuntur» $(\mathrm{V}, 10,1$, 24-27).

69 Advierte FANTinO: «Remarquons encore que l'âme ne subit pas une transformation identique à celle de la chair qui reçoit les qualités de l'Esprit» (La théologie, 336).

70 El olivo silvestre es echado al fuego. «Qui in carne sunt Deo placere non possunt» (Rm 8, 8; V, 10, 2, 52s).

$71 \mathrm{~V}, 10,2,55 \mathrm{~s}$.

$72 \mathrm{~V}, 10,2,59-64$
} 
nem vivitis, incipietis mori ${ }^{73}$, no rechazando la vida en la carne ${ }^{74}$, sino arrancando las concupiscencias de la carne que dan muerte al hombre. Y por esto añade: «Si autem Spiritu opera carnis mortificatis, vivetis: quicumque enim ducuntur Spiritu Dei, hi sunt filii Dei» ${ }^{75}$ (V, 10, 2, 53-71).

Según V, 6, 2, porque el Espíritu de Dios habita en nosotros (1Cor $3,16 s)$, el plasma es llamado templo de Dios. Pablo llama "templo» al cuerpo en el que habita el Espíritu. Y Jesús llamaba templo a su propio cuerpo (Jn 2, 19.21). Con los miembros de Cristo no se puede hacer miembros de una prostituta (1 Cor 6, 15). Por tanto habla de nuestro propio cuerpo (unido a una prostituta), de nuestra carne. Mientras el cuerpo persevera en la santidad y pureza, según dice el apóstol, es miembro de Cristo. "Templum igitur Dei, in quo Spiritus inhabitat Patris, et membra Christi non participare salutem, sed in perditionem redigi dicere, quomodo non maximae est blasphemiae?» ${ }^{76}$. Porque ahora, según $V, 8,1,1-17$, ya hemos recibido una parte del Espíritu de Dios para que nos disponga y nos prepare a la incorruptibilidad, acostumbrándonos ${ }^{77}$ poco a poco a captar y llevar a Dios: son las arras, parte del honor que Dios nos ha prometido: «Signati estis Spiritu promissionis sancto,

$73 \mathrm{~V}, 10,2,65 \mathrm{~s}$.

74 «Etenim ipse in carne cum esset scribebat eis» (V, 10, 2, 67).

$75 \mathrm{Rm} \mathrm{8,} \mathrm{13s;} \mathrm{V,} \mathrm{10,} \mathrm{2,} \mathrm{69-71.}$

$76 \mathrm{~V}, 6,2,74-77$.

77 Véase también III, 17, 1, 18-22 (el Espíritu se acostumbraba); 20, 2, $72-75$ (el Verbo de Dios y el hombre mutuamente se acostumbraban); IV, 14, 2, 48s; 20, 5, 101ss; 37, 7, 176s (maturecens); 38, 1, 1ss; V, 32, 1, 4-6; 35, 1, 17-21; 35, 2, 113-115, etc. Afirma Romero Pose: «El Espíritu acostumbrará a la carne a ser capaz de Dios. El Espíritu profético, en el A.T., dispondrá la plasis a acoger al Hijo de Dios, al Verbo. En el N.T., el Espíritu de adopción -propio del Hijo ya Carne glorificada- acostumbrará a la carne para que pueda recibir el Espíritu del Padre y entrar en comunión perfecta con el Creador» (Ireneo de Lión, Demostración, 34). "L'accoutumance, pour Irénée, n’est pas une formule commode, elle est le nerf de sa réflexion sur l'économie du salut, car elle lui permet d'exprimer le paradoxe de l'Amour divin se manifestant dans le temps humain, et le cheminement continu de l'homme marchant à la quête de Dieu et s'attachant à lui de plus en plus étroitement» (P. Evieux, «Théologie de l'accoutumance chez Saint Irénée», RSR LV (1967) 5-54, 53). «Leur accoutumance (del Verbo y del Espíritu) est évidemment au service de celle de l'homme. Car l'un et l'autre progressent dans une réciprocité constante. Dieu s'accoutume à l'homme et, d'un même mouvement, il donne à l'homme de pouvoir s'accoutumer à lui» (SESBoüÉ, Tout récapituler, 152-154). 
qui est pignus hereditatis nostrae» $(\mathrm{Ef} 1,13 \mathrm{~s})^{78}$. Las arras, que habitan en nosotros ya nos hacen espirituales y lo mortal es absorbido por la inmortalidad $^{79}$, no por eliminación de la carne sino por la comunión del Espíritu, que inhabita en nosotros. Aquellos a quienes Pablo escribía vivían en la carne, pero habían recibido el Espíritu de Dios, "en el que clamamos: Abba, Padre». Según V, 13, 4, 89-93, el Espíritu abraza a la carne, así nuestros corazones carnales han sido hecho capaces del Espíritu. Como dice Pablo, los corintios son la carta de Cristo escrita con el Espíritu del Dios vivo en las tablas carnales del corazón (2 Co 3, 3).

\section{ESPIRITUALES Y CARNALES}

En V, 8, 2 insiste Ireneo en que lo que hace al hombre espiritual es que nuestra sustancia (unión de alma y carne) reciba (assumens) el Espíritu de Dios. El apóstol llama espirituales a los que poseen las arras del Espíritu, se someten a él (no a las concupiscencias de la carne) y se comportan en todo razonablemente, pues el Espíritu de Dios habita en ellos. El apóstol llama carnales a los que rechazan el consejo del Espíritu y sirven los placeres de la carne viviendo irracionalmente sin ninguna inspiración del Espíritu divino ${ }^{80}$. Estos, según V, 8, 3, 86-93, por su incredulidad y lujuria, no obtienen el Espíritu divino y rechazan al Verbo vivificante, son llamados carnales y animales por el apóstol, etc. No se encaminan por la fe de manera estable hacia el Padre y el Hijo; no fijan la firmeza de su raíz en el Padre y el Hijo ${ }^{81}$.

Según V, 11, 1, en Ga 5, 19-21 Pablo, después de enumerar las obras de la carne, termina afirmando que los que cometen tales acciones no heredarán el reino de Dios. Proclama así con bastante claridad que «la carne y la sangre no pueden heredar el reino de Dios» (1 Co 15, 50), porque los que caminan según la carne no pueden vivir para Dios. Pablo añade a continuación las acciones espirituales que vivifican al hombre (Ga 5, 22s), a saber, el injerto del Espíritu. Así como el que haya progresado hacia lo mejor y producido el fruto del Espíritu es salvado de todos

\footnotetext{
$\mathrm{V}, 8,1,7-9$.

79 «Vos enim non estis in carne sed in Spiritu, siquidem Spiritus Dei habitat in vobis» $(\mathrm{Rm} \mathrm{8,9).}$

80 «Nihil aliud quam carnalia sentiunt» (V, 8, 2, 40s).

81 «Nunquam autem meditantur eloquia Dei, quemadmodum oportet, neque justitiae operibus sunt adornati» $(\mathrm{V}, 8,3,81-83)$. No obtienen, pues, el Espíritu divino.
} 
modos a causa de la comunión del Espíritu, así el que permanezca en las obras de la carne, el carnal, dado que no recibe el Espíritu de Dios, no podrá heredar el reino de los cielos. Pablo en 1Co 6, 9-11 enumera los que no heredarán ${ }^{82}$, el reino de Dios. Pero los Corintios ya han sido lavados, santificados, justificados en el nombre del Señor Jesús-Cristo y en el Espíritu de nuestro Dios. Pablo muestra por causa de qué perece el hombre, si perseverare en vivir según la carne, y por qué cosas es, a su vez, salvado. Las que salvan son el nombre de nuestro Señor Jesús Cristo y el Espíritu de nuestro Dios.

Y habiendo enumerado las obras de la carne sin el Espíritu, Pablo exclamó al final de su epístola: «Sicut portavimus imaginem ejus qui de limo est, portemus et imaginem ejus qui de caelis est (...), quoniam caro et sanguis regnum Dei possidere non possunt» (1 Co 15, 49s; V, 11, 2, 42-45) ${ }^{83}$. Cuando las obras de la carne se realizaban en nosotros, llevamos la imagen del que es de la tierra. Cuando creyendo en el nombre del Señor (Jesucristo) y recibiendo su Espíritu fuimos lavados, llevamos la imagen del celeste. Pero no fuimos lavados de la sustancia del cuerpo ni de la imagen del plasma sino de nuestra vetusta vida de vanidad. Por tanto, en aquellos miembros en que perecíamos por obrar lo de la corrupción, en esos mismos miembros somos vivificados por obrar lo que es del Espíritu (V, 11, 2, 45-59).

Al comienzo de $\mathrm{V}, 12,1$ prosigue afirmando nuestro autor que así como la carne es capaz de corrupción y de muerte, así también de incorruptibilidad y de vida. Una expulsa a la otra; presente una, perece la otra ${ }^{84}$. Si la muerte adueñándose del hombre ha expulsado a la vida, con mucha mayor razón la vida expulsará a la muerte y volverá al hom-

82 Hereditabunt; possidebunt.

83 A continuación dice Ireneo: «Hoc autem quod ait; "Sicut portavimus imaginem ejus qui de limo est", simile est illi dicto: "Et hanc quidem fuisti, sed abluti estis, sed sanctificati estis, sed justificati estis in nomine Domini Jesu Christi et in Spiritu Dei nostri”" (1 Co 6, 11; V, 11, 2, 46-49).

84 Comenta Orbe: «El hombre, en su primer existir, vivía con vida imperfecta (animal "per flatum vitae"), no con Vida perfecta (espiritual, "per spiritum"). Solo cuando se adentre en la vida del Espíritu excluirá la muerte (...) Solo la Vida y Muerte perfectas, en función de la Vida misma de Dios, se excluyen definitivamente» (Comentario I, 522). "Ireneo habla "per se" de la aptitud de la carne (o cuerpo) para los dos extremos: de Muerte o corruptela (eternas), totales; y de Vida o incorruptela (eternas), totales» (ib.). 
bre viviente para Dios. Si la muerte lo hizo morir, ¿por qué la vida no lo vivificará cuando sobreviniere? Cf. Is 25,8 . La prístina vida ha sido expulsada, porque había sido dada por un soplo y no por el Espíritu vivificante (hombre espiritual) ${ }^{85}$. Como ya vimos, el soplo se da a todo el que habita la tierra, pero el Espíritu propiamente a los que conculcan las concupiscencias terrenas (cf. Is 42, 5) (V, 12, 1, 1-2, 23). El Espíritu envuelve al hombre por dentro y por fuera, porque siempre permanece, nunca lo abandona. Primero lo animal, luego lo espiritual (1 Co 15, 46). Convenía que primero fuera plasmado el hombre y lo plasmado recibiera el alma, y así luego la comunión del Espíritu. Por eso "primus Adam factus est a Domino in animam viventem, secundus Adam in Spiritum vivificantem» $(1 \text { Co } 15,45)^{86}$. Como el primero declinando a lo peor perdió la vida, así este mismo, retornando a lo mejor y recibiendo el Espíritu vivificante, encontrará la vida $(\mathrm{V}, 12,2,33-46)^{87}$.

Pasando ahora a V, 12, 3s, nos dice Ireneo: lo que había muerto es lo vivificado. La sustancia de la carne, que había perdido (amiserat) el soplo de vida, estaba muerta ${ }^{88}$. El Señor vino para devolver a esta la vida, para que como todos morimos en Adán a título de animales, todos vivamos en Cristo a título de espirituales, no deponiendo el plasma de Dios sino las concupiscencias de la carne y recibiendo el Espíritu Santo. En Col 3, 5 Pablo dice que hagamos morir nuestros miembros terrestres: la fornicación, etc. Los que hacen tales cosas, como solo siendo carne y sangre, no pueden heredar el reino de los cielos. Por tanto, según el apóstol, hay que despojarse del hombre viejo con sus obras (Col 3, 9). Pero no por esto desecha el antiguo plasma. "Fructus autem operis spiritus est carnis salus» ${ }^{89}$. ¿Qué otro fruto visible ofrece el Espíritu invisible sino volver madura $^{90}$ a la carne y capaz de incorruptibilidad? Si «vivere in carne hic

85 «Reventó la Vida primera de Adán y del hombre viejo (no obstante ser divina), porque no fue otorgada -en plenitud, como en el N. T.- mediante el Espíritu (de adopción), sino - muy parcial e inicialmente, como cumplía al hombre recién creado, en el A. T.- mediante el soplo (de vida)» (ib., 533 respecto a V, 12, 1, 13s). $\mathrm{V}, 12,2,41-43$.

87 Cf. V, 1, 3, 75-83.

88 «La oveja evangélica simboliza al género humano; y aún mejor, al cuerpo del hombre» (Orbe, Comentario I, 567).

$89 \mathrm{~V}, 12,4,77 \mathrm{~s}$.

90 Respecto a que la carne necesite una maduración en el tiempo, véase Polanco, Gloria, 182-185. «Et tandem aliquando maturus fiat homo, in tantis maturescens 
mihi fructum operis est» (Flp 1, 22) ${ }^{91}$, el apóstol no menospreciaba la substancia de la carne en $\mathrm{Col} 3,9$, sino se refería a nuestra precedente manera de vivir, que envejece y se corrompe, y por eso añadió: «Et induentes novum hominem, eum qui renovatur in agnitionem secundum imaginem ejus qui creavit eum» $(\mathrm{Col} 3,10)^{92}$. El que se renueva es el mismo hombre que antes estaba en la ignorancia de Dios. Y en V, 14, 4 añadirá Ireneo: si, por tanto, la carne y la sangre nos procuran la vida, no ha sido dicho de la carne y de la sangre el que no pueden heredar el reino de Dios, sino de los actos carnales que, desviando al hombre al pecado, le privan de la vida. En Rm 6, 12s dice Pablo que no reine el pecado en nuestro cuerpo mortal sino que nos presentemos a Dios como muertos retornados a la vida. Con los miembros con que servíamos al pecado y fructificábamos para la muerte, con esos mismos quiere que sirvamos a la justicia y fructifiquemos para la vida.

\section{El PODER DE Dios PARA Resucitar la CARNe}

Dios Padre ${ }^{93}$ reviste esto mortal con la inmortalidad, y regala gratuitamente la incorruptibilidad a lo corruptible, porque el poder de Dios se consuma en la debilidad (V, 2, 3, 57-62) ${ }^{94}$. En V, 3, Ireneo comienza citando 2

ad videndum et capiendum Deum» (IV, 37, 7, 175-177). «Patre quidem bene sentiente et jubente, Filio vero ministrante et formante, Spiritu vero nutriente et augente, homine vero paulatim proficiente et perveniente ad perfectum, hoc est proximum infecto fieri (...)»(IV, 38, 3, 73-78). «Pour Irénée, l'opus Spiritus est la "maturation" ou la "préparation" de la chair à la vision de la lumière paternelle incorruptible, par une spiritualisation progressive de la chair, grâce à l'incarnation du Verbe et à la Pentecôte de l'Esprit sur l'Église» (Andia, HOMO VIVENS, 334).

$91 \mathrm{~V}, 12,4,81$.

$92 \mathrm{~V}, 12,4,86-88$. «Secundum imaginem conditoris, recapitulationem manifestavit

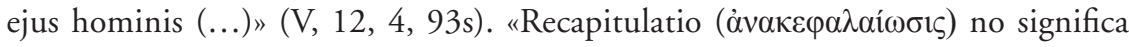
resumen ni restitución, sino realización o consumación»(Orbe, Comentario I, 584s).

93 Véase Orbe ad l.c. respecto al antecedente de 'qui'.

94 «Ex illius magnitudine, sed non ex nostra natura, habemus in aeternum perseverantiam» (V, 2, 3, 66s). Cf. V, 6, 2, 78-7, 1, 5 (1 Co 6, 13s). Respecto a la mayor distancia de la carne respecto a Dios, siendo menor la del alma, expresa A. Orbe: «Ireneo discurre enteramente al revés. La vecindad de substancia compromete la munificencia de la Dispensación divina. Su postulado, implícito, es: cuanto más se aleje en lo natural, la substancia del hombre de la divina, mejor resplandecerá lo divino en la Economía humana y más digna será de Dios» («Ireneo de Lyon», 
Cor 12, 7-9: «Virtus enim in infirmitate perficitur» ${ }^{95}$. Rechazan el poder de Dios los que viendo la debilidad de la carne no consideran el poder de quien la resucita de entre los muertos. Porque si no vivifica lo mortal y no eleva lo corruptible a la incorruptibilidad, Dios ya no es poderoso. Pero lo es porque modeló al hombre del lodo de la tierra y es más difícil hacer algo de lo que no existía que reintegrar los elementos en la vida dada por él. Por otro lado, la carne es capaz de recibir y contener el poder de Dios. En ella (en su creación) se ve el arte y la sabiduría de Dios. Participa, por tanto, de su poder. "Nam virtus ejus (de Dios) qui vitam praestat in infirmitate perficitur, hoc est in carne ${ }^{96}$. ¿Cómo dicen, los contradictores, que la carne es incapaz de tener parte en la vida, si ellos mismos están vivos? Si esta vida temporal, que es bastante más débil que aquella eterna, sin embargo, es tan poderosa que vivifica nuestros miembros mortales, ¿̨por qué aquella vida eterna no vivificará esta carne que ya esté ejercitada y acostumbrada a llevar la vida? Por tanto, que la carne sea capaz de participar de la vida, se prueba porque vive ${ }^{97}$. Siendo Dios poderoso para vivificar su plasma y pudiendo la carne ser vivificada, ¿qué queda que prohíba que ella reciba la incorrupción, que es una vida larga ${ }^{98}$ y sin fin otorgada por Dios?

Refrendando el poder de Dios para dar una vida larga, sin $f^{99}$, en V, 4 y 5 expone Ireneo el tema de que el Creador, Padre bondadoso, es el que vivifica los cuerpos y ha dado longevidad a algunos. En cambio ahora, concluye nuestro autor, algunos ignoran el poder de Dios y su promesa, impugnando su propia salvación, porque estiman imposible que Dios pueda, resucitando los cuerpos, darles una perseverancia eterna $^{100}$. La exposición de Ireneo fluye a grandes líneas de la manera siguiente. Según V, 4, el supuesto Padre bueno de los herejes (otro que el Creador), si no puede vivificar nuestros cuerpos, sería débil, inútil y

1101, en A. di Berardino Diccionario Patrístico y de la Antigüedad Cristiana [Verdad e Imagen 97], Sígueme, Salamanca 1991s, 2 vol., 1098-1105).

95 Véase también V, 7, 2, 42-45: “Seminatur (la carne) in infirmitate, surgit in virtute" (1 Co 15, 43): in infirmitate quidem sua, quoniam cum sit terra in terram vadit; virtute autem Dei, qui eam suscitat a mortuis. "Seminatur corpus animale, surgitur corpus spiritale” (1Co 15, 44).

$96 \mathrm{~V}, 3,3,60$ s.

97 «Vivit enim inquantum eam Deus vult vivere» (V, 3, 3, 85s).

98 Según las versiones.

99 Véase Dem 72.

$100 \mathrm{~V}, 5,2,59-62$. 
negligente, por no decir envidioso. Contrariamente, es más poderoso y verdaderamente bueno el Creador que vivifica a todo el hombre ${ }^{101}$. ¿Qué causa podría haber para que el Padre no vivifique los cuerpos? Esa causa tendría que ser más poderosa que su bondad; y el Padre no sería libre y Señor en su dictamen. De hecho, los cuerpos viven tanto cuanto Dios quiere. En V, 5 trae Ireneo, como ejemplo, la longevidad que Dios quiso para algunos. Así por ejemplo, Enoch fue transpuesto en el cuerpo en que agradó a Dios, prefigurando la transposición (transferencia) de los justos. Elías fue "asumido» tal cual estaba en la sustancia del plasma, profetizando la «asunción» de los espirituales ( $\pi v \varepsilon v \mu \alpha \tau \iota \kappa \tilde{\omega} v)$. Asunción y transposición por las mismas manos por las que fueron plasmados en el origen, pues estaban acostumbradas en Adán a concertar, aprehender y llevar a cuestas su plasma y colocarlo donde ellas quisiesen ${ }^{102}$. Por eso, según los "presbíteros» (discípulos de los apóstoles), los transpuestos lo han sido al paraíso (preparado para los hombres justos y que tienen el

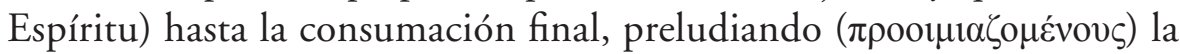
incorruptibilidad $^{103}$. La longevidad y el rapto de Elías lo realizó la mano de Dios (el Hijo de Dios [Dn 3, 92]), como en el horno ardiente ${ }^{104}$. La debilidad de la carne no es más fuerte que la voluntad de Dios (Creador): lo que entre los hombres resulta imposible, es posible para Dios.

Ya vimos que lo que había muerto es lo vivificado ( $\mathrm{V}, 12,3,47-$ 57). En V, 12, 5, 110-13, 1, 28, Ireneo lo remacha. Así, el Pablo que evangelizaba era el mismo que había perseguido a la Iglesia (cf. Ga 5, 15s). Igualmente a propósito de las curaciones de Jesús, como los ciegos curados por el Señor: por los mismos ojos que no veían, ahora al ver daban gracias. Y todos los que curó recibían sanos los miembros que tenían desde el útero. Porque el artífice del universo, el Verbo de Dios, que desde el principio plasmó al hombre, encontrando su plasma arruinado por la maldad, lo curó de todas las maneras posibles: cualquiera de sus miembros ${ }^{105}$, pero también reintegró sano, de una vez, a todo el hombre, hombre perfecto, en orden a la resurrección. ¿Por qué sanaría

\footnotetext{
101 Aquí vivifica nuestros cuerpos mortales (cf. Rm 8, 11) y prometió la resurrección por medio de los profetas.

102 Véase también III, 17, 1, 18-22; 20, 2, 72-75; V, 16, 1, 17-20, etc.

103 Más adelante: «Ad exemplum futurae longitudinis dierum» $(\mathrm{V}, 5,2,56)$.

${ }_{104}$ Más adelante: «Velut manu Dei ad ostentionem virtutis ejus» (V, 5, 2, 58s).

105 Restaurándolo «sicut in initio plasmatum est» (V, 12, 6, 124s).
} 
y restituiría los miembros de carne a su forma primera si no iban a ser salvados? Una utilidad temporal no sería gran favor. ¿Cómo no es capaz la carne de recibir de él la vida, si de él recibe la curación? En efecto, la vida se produce (efficitur) por la sanación, y la incorrupción por la vida. Por consiguiente, el que da la sanación, también da la vida, y el que da la vida reviste a su plasma de incorrupción. Los resucitados por Jesús resucitaron en los cuerpos en que habían muerto. De lo contrario, no serían esos mismos muertos los que resucitaron. El Señor dio la mano al joven muerto y le habló a él; llamó a Lázaro y salió el muerto atado de pies y manos. Por tanto, así como fueron sanados los miembros que habían estado enfermos antes y resucitaron los muertos en sus mismos cuerpos, recibiendo la sanación y la vida dadas por el Señor, prefigurando lo eterno por medio de lo temporal y mostrando que es el mismo el que puede dar a su plasma la sanación y la vida, para que igualmente su palabra sobre la resurrección fuera creída, así también los muertos resucitarán al final ${ }^{106}$, como dice en Jn $5,25.28 \mathrm{~s}^{107}$.

\section{LA RESURRECCIÓN DE LA CARNE}

Se ha destacado en este trabajo la centralidad de la Encarnación para la salvación de la carne. Pero obviamente, esta centralidad se concreta gracias a la resurrección de Jesús. Así en V, 13, 4, 103-115, trae la cita de 1 Co 15, 13-21: si los muertos no resucitan, tampoco Cristo resucitó, vana es nuestra $\mathrm{fe}^{108}$. Quisiera ahora destacar, entre otros textos, V, 6, 2, 78-7, 1, 36, donde cita 1 Co 6, 13s: «Deus autem et Dominum suscitavit, et nos suscitabit per virtutem suam» ${ }^{109}$. Como Cristo resucitó

\footnotetext{
106 «In novissima tuba» (cf. 1 Co 15, 52).

107 «Veniet hora, in qua omnes mortui qui in monumentis sunt audient vocem Filii hominis, et exient qui bona fecerunt in resurrectionem vitae, et qui mala operati sunt in resurrectionem judicii».

108 «Nunc autem Christus resurrexit a mortuis, primitiae dormientium: quoniam enim per hominem mors, et per hominem resurrectio mortuorum» (1 Co 15, 20s). "La misma Caro rutila que se presentaba a los ojos del Creador como arquetipo de Adán, pasa a ser origen - por efusión de su Espíritu- de la humana deificación, y es constituido Mediador entre Dios y los hombres, entre el Spiritus Deus y el homo caro; como quien recibe "secundum carnem" del Padre, el Espíritu que derrama luego en la de sus hermanos los hombres y los dispone para las alturas divinas de la suya propia» (Orbe, Ireneo de Lyon, 1100).

109 "Corpora nostra non ex sua substantia, sed ex Dei virtute suscitantur» (V, 6, 2, 79s).
} 
en la sustancia de su carne y mostró a sus discípulos las señales de los clavos, señales de que era su propia carne la que resucitaba, así también (Dios) nos resucitará por su poder. Dice Pablo en Rm 8, 11: «Si autem Spiritus ejus qui suscitavit Jesum a mortuis habitat in vobis, qui suscitavit Christum a mortuis vivificabit et mortalia corpora vestra ${ }^{110}$. No se refiere a las almas que son incorporales, porque el soplo de vida que constituyó al hombre en alma viviente es incorporal; la substancia de esta alma es inmortal ${ }^{111}$. Tampoco el cuerpo mortal es el espíritu. Por tanto el plasma, la carne, es el cuerpo mortal que vivificará Dios. (La carne) es la que muere y vuelve a sus elementos primitivos; no muere ni el alma (hálito de vida) ni el espíritu (pues es simple; no puede disolverse; es vida de cuantos lo reciben). Por tanto, la muerte se manifiesta en la carne: sin hálito ni alma, poco a poco se disuelve en la tierra de la que fue tomada. (La carne) es mortal, de la que se dice: Dios «vivificabit et mortalia corpora vestra» $(\operatorname{Rm} 8,11)^{112}$. Como afirma 1 Cor 15,42 , la carne sembrada en la corrupción resucitará en la incorrupción ${ }^{113}$.

Como el grano de trigo, prosigue Ireneo en $\mathrm{V}, 7,2$, son nuestros cuerpos los que se pudren en la tierra ${ }^{114}$. Como dice 1 Co 15,43 , sembrados en ignominia, resucitan en gloria. ¿Qué hay más innoble que la carne muerta, o más glorioso que esta cuando surge y recibe la incorrupción? Conforme a 1 Cor 15,43 , se siembra en debilidad y resucita en poder (el poder es el de Dios que la resucita de entre los muertos). Según 1 Cor 15, 44, se siembra cuerpo animal y surge un cuerpo espiritual. Ni al alma ni al espíritu se refiere esto, sino a los cuerpos muertos. Estos son los cuerpos animales, que participan del alma; los que mueren cuando la pierden. Después se hacen cuerpos espirituales resucitando por el Espíritu, de manera que por el Espíritu tienen vida permanente en el conocer cara a cara $(1 \text { Cor } 13,12)^{115}$. Con gozo inenarrable $(1 \mathrm{P}$

${ }_{110} \mathrm{~V}, 6,7,6-8$. Cf. también V, 10, 2, 60-64.

111 Véase II, 34, 2-4.

$112 \mathrm{~V}, 7,1,32$.

113 Tiene primero que morir para ser vivificada (1 Co, 15, 36).

${ }^{114}$ Y en V, 9, 4, 80-82: «Scilicet membra hominis quae et corrumpuntur in terra. Haec autem possidentur a Spiritu translata in regnum caelorum». Son poseídos como herencia

115 Como ya vimos, en V, 1, 3, 78-81 a propósito de la Encarnación, habla del hombre, conocedor (capientem) del Padre perfecto. Comenta Orbe ad l.c.: «El Padre, en sí, es "incapabilis", imposible de ser intuitivamente conocido por el hombre. 
$1,8)$ nuestro rostro verá el rostro de Dios y se gozará con la vista de su gozo (Dios) (V, 7, 2, 36-59). Si ahora clamamos Abba, Padre, ¿qué ocurrirá, entonces, cuando resucitando lo veamos cara a cara, cuando todos nuestros miembros con profusión prorrumpan en un himno ${ }^{116} \mathrm{de}$ exultación glorificando a aquel que los ha resucitado de entre los muertos y les ha donado la vida eterna? Si las arras abrazando al hombre por todos lados ( $\sigma v \mu \pi \varepsilon \rho \imath \lambda \alpha \mu \beta \alpha ́ v \omega v)$ ya lo hace decir Padre, ¿qué hará toda la gracia del Espíritu ${ }^{117}$, que les será dada a los hombres por Dios? Ella nos hará semejantes a él y llevará a cabo la voluntad del Padre, porque hará al hombre a imagen y semejanza de Dios (V, 8, 1, 16-26 $\left.6^{118}\right)$. Ya habíamos visto, a propósito de la Eucaristía, que nuestros cuerpos nutridos por ella, aunque se disuelvan en la tierra, resurgirán; que el Verbo de Dios les otorga la resurrección para gloria del Padre; que este último los reviste gratuitamente de inmortalidad e incorruptibilidad; que el poder de Dios se consuma en lo débil (V, 2, 3, 57-62).

Pablo contradice la interpretación herética de 1 Co $15,50^{119}$ según la cual ni la carne ni la sangre pueden heredar el reino de Dios, al aña-

Pero se hizo "capabilis" en el Hijo encarnado, al unirse al hombre el Espíritu de Dios en la carne del Verbo a fin de comunicarse a los demás». Cf. V, 8, 1, 1-3.

116 Cf. también V, 13, 3, 77s.

117 Y respecto al Espíritu, que abraza a la carne, se pregunta Ireneo, partiendo de 2 Co 3, 3: «Si ergo nunc corda carnalia capacia Spiritus fiunt, quid mirum si in resurrectione eam quae a Spiritu datur capiunt vitam? De qua resurrectione Apostolus in ea quae est ad Philippenses (3,10s) ait: "Cooneratus morti ejus, si quo modo occurram ad resurrectionem quae est a mortuis"» (V, 13, 4, 90-97). ¿En qué otra carne mortal puede manifestarse la vida sino en esta sustancia que es también matada por la confesión de Dios? (V, 13, 4, 99s). Véase IV, 20, 4, $91 \mathrm{~s}$.

118 «La creación del hombre se realiza plenamente y concluye solo con la visión del Padre» (J. J. Ayán, Ireneo de Lyon, p. 934s, en A. Di Berardino y otros, Literatura Patrística (San Pablo, Madrid 2010), 928-936). Y antes este mismo autor había dicho (ib. 934): «Por eso "habrá un nuevo cielo y una nueva tierra" (Is 65, 17), en la cual el hombre se mantendrá nuevo, siempre relacionándose con Dios de modo nuevo" (Adv Haer V, 36, 1)».

119 Los ciegos y ridículos herejes, respecto a que «Caro et sanguis regnum Dei possidere non possunt» (1 Co 15, 50), no perciben ni escrutan el valor de las expresiones del Apóstol: así mueren derribando, en cuanto puedan, la universal disposición de Dios. Refieren estas palabras a la carne y no a las obras carnales (V, 13, 2, 37-3, 45). Vanos son los que desprecian la universal disposición de Dios «et carnis salutem negant et regenerationem ejus spernunt, dicentes non eam capacem esse incorruptibilitatis» (V, 2, 2, 18-21). Cf. V, 10, 1, 17-19; 14, 2, 44-46. 
dir después en 1 Co 15, 53-55: «Oportet enim corruptibile hoc induere incorruptelam et mortale hoc induere immortalitatem. Cum autem mortale hoc induerit immortalitatem, tunc fiet sermo qui scriptus est: Absorta est mors in victoria. Ubi est mors aculeus tuus? Ubi est mors victoria tua?» ${ }^{120}$. Dice Ireneo que esto se cumplirá, cuando esta carne mortal y corruptible en que tiene también lugar la muerte, y que está oprimida por algún dominio de la muerte, ascendiendo a la vida revista la incorrupción e inmortalidad. Entonces será verdaderamente vencida la muerte, cuando la carne, que era su presa, salga de su dominio. También lo expresa Pablo en Flp 3, 20s: "Nostra autem conversatio in caelis est, unde et Salvatorem exspectamus Dominum Jesum, qui transfigurabit corpus humilitatis nostrae conforme corpori gloriae suae ita ut possit secundum operationem virtutis suae» ${ }^{121}$. El cuerpo de humildad que transfigurará el Señor conformándolo a su cuerpo de gloria es manifiestamente el cuerpo que es carne. Pero su transfiguración, porque siendo mortal y corruptible es hecho inmortal e incorruptible, no es en virtud de la propia sustancia sino de la acción del Señor que puede vestir lo mortal con la inmortalidad y lo corruptible con la incorruptibilidad. Y por eso dice el Apóstol en 2 Co 5, 4s: «Ut absorbeatur mortale a vita. Qui autem perficit nos in hoc ipsum, Deus, qui dedit nobis pignus Spiritus» ${ }^{122}$. Clarísimamente esto lo dice de la carne, porque ni el alma ni el Espíritu son mortales. Será absorbido lo mortal por la vida, cuando la carne ya no permaneciere muerta sino viva e incorrupta. Dios nos dispone (perficit) para esto: "Glorificate Deum in corpore vestro" (1 Co $6,20)^{123}$. Dios es el autor de la incorruptibilidad $(\mathrm{V}, 13,3,44-81)^{124}$. Y

${ }^{120} \mathrm{~V}, 13,3,48-53$. Cf. también V, 10, 2, 51-56.

$121 \mathrm{~V}, 13,3,59-63$.

$122 \mathrm{~V}, 13,3,72-74$

$123 \mathrm{~V}, 13,3,79 \mathrm{~s}$.

124 El Padre es el único óptimo y bueno, el que da la incorruptibilidad, según V, 1, 1, 12-14. Véase IV, 20, 2, 49-52 (et ut in carnem Domini nostri occurrat paterna lux, et a carne ejus rutila veniat in nos, et sic homo deveniat in incorruptelam, circumdatus paterno lumine); IV, 38, 3, 82s (Visio autem Dei efficax est incorruptelae). «Homines igitur videbunt Deum ut vivant, per visionem inmortales facti et pertigentes usque in Deum» (IV, 20, 6, 131-133), etc.

Respecto a IV, 20, 5, 109-117, comenta Polanco (Gloria, 174): «El texto continúa explicando que el hombre llega a ver a Dios de tres maneras: Prophetice, adoptive, paternaliter. Es una gradual deificación del ser humano. El proceso de visión de Dios es gradual, donde la forma profética es la visión por medio del Espíritu que 
concluirá Ireneo este capítulo 13 afirmando: Por tanto, en todo esto, o dirán (los herejes) que el Apóstol se contradice respecto a que «la carne y la sangre no pueden heredar el reino de Dios» (1 Co 15, 50), o se verán obligados a pervertir el sentido de los dichos. Se esforzarán por interpretar de otra forma 1 Co 15, 53 $3^{125}, 2$ Co 4, $11^{126}$, y todos los otros pasajes en que el Apóstol con claridad proclama la resurrección e incorruptibilidad de la carne (V, 13, 5, 116-129).

\section{A MODO DE CONCLUSIÓN}

Habiendo expresado el pensamiento de Ireneo sobre la salvación de la carne recorriendo las citas según diversos tópicos en la parte de su obra que estudiamos, es conveniente ahora una breve conclusión que alumbre un poco la trabazón de este pensamiento en algunos de sus puntos principales. Todo está dirigido contra los herejes, es un Adversus haereses. Después de un párrafo de claro sabor antidoceta, nombra en particular a valentinianos, ebionitas y ataca a marcionitas. Caballo de batalla de los adversarios es 1 Co, 15, 50: ni la carne ni la sangre pueden heredar el reino de Dios. Ireneo responde que este texto se refiere a los que viven según las concupiscencias de la carne, pero no a los que han muerto a ellas, para que en su carne se manifieste la vida de Cristo. No es, por tanto, la sustancia de la carne la que no puede heredar el reino. Por lo demás, Pablo a menudo usa carne y sangre en un sentido diferente a 1 Co 15, 50, en referencia a Cristo, quien nos redimió con su sangre. Con la mala interpretación de los herejes, al negar estos la salvación de la carne (cuerpo, plasma), arruinan

predispone y prepara al hombre para encontrarse con el Hijo. El encuentro con el Hijo hace al hombre hijo adoptivo, gracias al Espíritu adoptivo que la encarnación y resurrección gloriosa del Hijo han donado al hombre y hecho rutilante a toda carne en Cristo (IV, 20, 2). Esta condición adoptiva dispone, a su vez, a la carne humana para recibir el Espíritu directamente del Padre, para poder ver al Padre y así recibir la incorrupción para la vida eterna. El Espíritu paterno configura a la carne con la misma vida divina, es decir, con la incorruptibilidad, inmortalidad y gloria de Dios, en un camino largamente progresivo, en donde la visión propiamente será solo en la escatología, pero de alguna manera ya ha comenzado desde antiguo». Véase Dem 7.

125 «Oportet enim corruptibile hoc induere incorruptelam, et mortale hoc induere immortalitatem» $(\mathrm{V}, 13,5,123-125)$.

126 «Ut vita Jesu manifestetur in carne mortali nostra» (V, 13, 5, 125s). En V, 13, 4, 82-89 cita 2 Co 4, 10s para confirmar que es el cuerpo de carne el que resucita. 
totalmente el plan, la disposición, de Dios; arruinan su plasmación, a la que vino a salvar el Verbo haciéndose hombre.

El plasma humano no vino de otro Dios, diferente del Dios bueno y Creador, cuyo amor es omnipotente, sino que Dios creó el mundo y plasmó al hombre por medio de sus dos manos, el Hijo y el Espíritu. Detrás de ellas está el Padre que nos predestina a ser, y nos da el don de la incorrupción. El Verbo es llamado artífice, ministro, y es anterior a la creación; el Espíritu es el que cohesiona la creación, y de él participa íntimamente todo hombre viviente. 'Viviente' se refiere a la vida eterna, que es muy superior a la vida temporal, que depende del simple soplo de Dios. En contraposición al soplo temporal, el Espíritu es divino, eterno. Adán, por su pecado, perdió la vida primigenia y quedó sometido a la muerte.

Pero el hombre nunca escapa de las dos manos del Padre que lo siguen conduciendo. Así estas intervienen en la encarnación salvadora. El Verbo, viniendo a lo propio (a lo que había él mismo plasmado) se hace hombre verdadero, de carne y sangre, para que nosotros llegáramos a ser lo que él es, recapitulándonos y reconciliándonos con Dios, restableciendo el antiguo plasma. Dios desciende y el hombre asciende. El Verbo, que es Dios, es también perfecto hombre por la sustancia de la carne tomada de María, sobre la que desciende el Espíritu de Dios. Cristo nos redime con su sangre y además en la Eucaristía, nos nutre con su cuerpo y con su sangre. Dado que en Cristo se unieron la carne y la divinidad, y el restablecimiento de nuestra carne, parece blasfemia decir que la carne no es capaz de salvación. Con la verdad de la Encarnación, perece toda doctrina herética. Ireneo termina la sección que estudiamos del libro, diciendo que nos aferremos a la cabeza del cuerpo, es decir a su venida carnal. Este es el gran centro antiherético. Y la Encarnación se nos muestra, pues, como necesaria para nuestra redención, salvación, reconciliación, comunión con Cristo, recapitulación, restauración, etc.

La concepción herética era dualista respecto a la carne; la de Ireneo es unitaria. Si hay salvación del hombre, tiene que salvarse la carne. Porque hombre (como lo vemos en Cristo en la plenitud de su sentido), hombre perfecto o espiritual, es el compuesto de carne y alma que participa del Espíritu de Dios, al que está íntimamente unido. El alma está como al medio, y puede seguir a la carne (hombre carnal sin salvación) o al Espíritu (hombre espiritual). Siguiendo a Pablo, Ireneo enumera las acciones carnales y los frutos del Espíritu. Hemos dicho que el hombre 
es la unión de los tres componentes, y hay una sola y misma salvación para los tres. Ni el Espíritu, ni el alma, ni la carne, por separados, son el hombre. Ireneo concede que el hombre fue primero animal (psíquico diríamos nosotros) y después espiritual, es decir, propiamente hombre.

La acción de las manos de Dios no se detiene, sino que culmina (perficere) con la transformación final de la carne en incorruptible, inmortal. Esto es un don del Padre. El hombre que siempre fue a imagen de Dios por la carne, recupera plenamente la similitud con Dios. Igual que en Cristo, en él resplandece de nuevo la imagen y semejanza con Dios, con que fue creado. La semejanza le viene por el Espíritu. ¿Cómo se puede decir que no es capaz de salvación en su carne, con la que conforma una sola unidad? El tema de la imagen y semejanza, junto con las manos de Dios, acompañan al hombre desde la creación a la resurrección, pasando por la Encarnación restauradora. Ambos temas muestran la unidad de la economía divina, que los herejes arruinan.

Más aún, en su visión unitaria, a ratos tiende Ireneo a que la vida eterna es como una prolongación de esta vida. Dios es el que dio la longevidad que él quiso, en la primitiva antigüedad, o en el caso de Henoch y Elías. Así llegará nuestro autor a llamar la vida eterna, perseverancia eterna. Pero advierte, respecto a los justos difuntos, que según la tradición de los Presbíteros esperan en el paraíso la resurrección, que ellos son solo figura de la incorruptibilidad del reino de Dios. Y respecto a la vida, dice que la eterna es muy superior respecto a la temporal. En otro pasaje afirma que por la curación se produce la vida y por la vida la incorruptibilidad, pero acababa de distinguir entre sanación temporal, no de gran valor, y la salvación, siendo el mismo el donante. Los resucitados por Jesús solo prefiguraban lo eterno por medio de lo temporal. Otro argumento de Ireneo, que va en el sentido unitario, es uno 'ad hominem', dirigido a los herejes. ¿Cómo estando ellos vivos en su carne, participando por tanto de la vida, dicen que la carne está excluida de la vida? Las sanaciones de Jesús desembocan en vida y esta en incorruptibilidad. Pero aclara que sus resurrecciones de muertos, son para que le creamos su promesa respecto a nuestra resurrección futura. Esta especie de tendencia al emparejamiento con la creación, al que tiende Ireneo, muestra el gran peso de esta (de la carne) en su visión global. Con todo, insistirá en que la incorruptibilidad es un don de Dios. 
Pero la salvación de la carne depende del Espíritu. El es el que conforma y salva a la carne; el que constituye al hombre en perfecto y espiritual. El Espíritu fue infundido en Pentecostés y nos hace hijos adoptivos de Dios. Sus arras ya las tenemos. Somos templos del Espíritu, quien es como el esposo del templo y se goza en él. Ya somos también miembros del Verbo, quien inhabita en nosotros y nos renueva. El Espíritu, que está pronto, absorbe la debilidad de la carne. Produce la vida. El Espíritu es como el injerto que nos va transformando, nos va madurando para la incorrupción; nos va acostumbrando poco a poco a captar a Dios. La misma sustancia del cuerpo ya es capaz del Espíritu. Entonces no somos carnales sino que llevamos la imagen del hombre celeste. Como vemos, el Espíritu no es lo que se opone a la carne, como piensan los herejes, sino que, en íntima unión, la espiritualiza y la prepara para la resurrección. Por la visión de Dios se recibe el don de la incorruptibilidad. Todo esto corresponde a la mirada unitaria de Ireneo. El fruto del Espíritu es la salvación de la carne.

El trabajo de las dos manos culmina en la resurrección de la carne, obviamente en los mismos cuerpos. Así como Jesús sanaba los miembros que estaban enfermos y no otros, así es conveniente que con los mismos miembros con que pecamos seamos salvados. Nuestra resurrección de la carne forma una unidad con la de Jesús, en la que se funda. Si nosotros no resucitamos, Cristo tampoco resucitó y vana es nuestra fe. ¿Tiene poder Dios para resucitarnos? Por supuesto, porque es el Creador. Vuelve a manifestarse el peso de la creación contra los herejes que separan a Dios del Creador. Y es más fácil resucitar que crear. La resurrección es como el grano de trigo que se pudre y después vuelve a surgir. Así el poder de Dios culmina en la debilidad de la carne. Si morimos con Cristo, la vida de él se manifestará en nuestra carne. Somos conformados a su cuerpo de gloria. Hay una transformación de nuestra carne que pasa a ser incorruptible e inmortal. Lo corruptible se reviste de incorruptibilidad. Es la victoria de la vida sobre la muerte. La vida ha expulsado definitivamente a la muerte. Se trata de la vida eterna, de la perseverancia para siempre. Se ve a Dios cara a cara y explota el gozo y un himno colectivo de alabanza al Padre. Somos capaces de conocer (capere) al Padre perfecto, en cuyo seno están todos reunidos. Todo es para gloria del Padre, quien, autor de la incorruptibilidad, ha salvado a la carne por medio de sus dos manos. Queda plenamente restablecida la imagen y semejanza. El Espíritu posee entonces a la carne como herencia. 
Resumen: El autor analiza el texto de Adversus Haereses V, 1-14, que forma una unidad determinada y presenta su contenido agrupando por los tópicos señalados con letra versales, como Las manos del Padre, El Espíritu y la debilidad de la carne, etc. Trata que resuene el texto de Ireneo, siendo lo más fiel posible a él, aunque constantemente repita, como repite Ireneo. En la economía, que se extiende desde la creación hasta la consumación final, el Espíritu es la salvación de la carne, gracias a la encarnación de Cristo. En polémica antiherética, son los carnales, y no la carne, los que no heredarán el reino.

Palabras clave: Ireneo, imagen y semejanza, carne y Espíritu, encarnación, economía trinitaria, resurrección

Abstract: The author analyzes the text of Adversus Haereses V, 1-14, a particular unit, and presents its content grouping by capitalized topics, like the Hands of the Father, the Spirit and the weakness of the flesh, etc. He attempts to resonate the text of Irenaeus, being as faithful as possible to him, but constantly repeating, as Irenaeus repeats. In the economy, extending from the creation to the final consummation, the Spirit is the salvation of the flesh through the incarnation of Christ. In antiheretical polemics, it is the men of flesh, not the flesh, who will not inherit the kingdom.

Keywords: Irenaeus, image and likeness, flesh and Spirit, incarnation, trinitarian economy, resurrection 